Published in final edited form as:

Hou, I.-C.-Y., Hu, Y., Narita, A., \& Müllen, K. (2018). Diels-Alder polymerization: a versatile synthetic method toward functional polyphenylenes, ladder polymers and graphene nanoribbons. Polymer Journal, 50(1), 3-20. doi:10.1038/pj.2017.69.

\title{
Diels-Alder polymerization: a versatile synthetic method toward functional polyphenylenes, ladder polymers and graphene nanoribbons
}

\author{
Hou, I.-C.-Y., Hu, Y., Narita, A., \& Müllen, K.
}

This article may be used for non-commercial purposes in accordance with publisher's Terms and Conditions for Self-Archiving. 


\title{
Diels-Alder Polymerization: A Versatile Synthetic Method
}

\section{Toward Functional Polyphenylenes, Ladder-Polymers and}

\section{Graphene Nanoribbons}

\author{
Ian Cheng-Yi Hou ${ }^{1}$, Yunbin Hu ${ }^{1}$, Akimitsu Narita ${ }^{1, *}$ and Klaus Müllen ${ }^{1,2, *}$ \\ ${ }^{1}$ Max-Planck-Institut für Polymerforschung, Ackermannweg 10, D-55128 Mainz, Germany \\ ${ }^{2}$ Institute of Physical Chemistry, Johannes Gutenberg University Mainz, Duesbergweg 10-14, \\ D-55128 Mainz, Germany
}

Email: narita@mpip-mainz.mpg.de, muellen@mpip-mainz.mpg.de

\begin{abstract}
The Diels-Alder reaction has been widely employed in synthetic organic chemistry since its discovery in 1928. The catalyst-free nature, functional group tolerance and high efficiency of the Diels-Alder reaction make it also promising for the fabrication of functional polymeric materials. In particular, a large variety of functional polyphenylenes (polymer structures mainly consisting of phenylenes) and ladderpolymers (double stranded polymers with periodic linkages connecting the strands) have been achieved by this method, showing potential applications such as polymer electrolyte membranes and gas separation. More recently, tailor-made polyphenylenes prepared by Diels-Alder polymerization have been utilized as precursors of structurally well-defined graphene nanoribbons (ribbon-shaped nanometer-wide graphene segments) with different widths, demonstrating large length $(>600 \mathrm{~nm})$ and tunable electronic band gaps. This article provides a comprehensive review for the use of Diels-Alder polymerization to build functional polyphenylenes, ladder-polymers and graphene nanoribbons.
\end{abstract}

Keywords: Diels-Alder polymerization/ graphene nanoribbon/ ladder-polymer/ polyphenylene/ polymer electrolyte membrane

\section{Introdution}

The Diels-Alder (D-A) reaction, named after Otto Diels and Kurt Alder ${ }^{1}$, is clearly one of the most important and commonly used organic processes in synthetic organic chemistry. ${ }^{2}$ This concerted [4+2] cycloaddition leads to six-membered-ring products with controllable stereochemistry. The D-A reaction is, in principle, metal/catalyst 
free, and further features thermal reversibility, rapid kinetics, high versatility, and wide functional group tolerance. ${ }^{3,4}$ These characteristics make the D-A reaction a suitable choice for constructing a wide range of polymeric materials, including discrete and soft supramolecular networks, semi-rigid polyphenylenes (PPs), rigid ladder-polymers, biocompatible and stimuli-responsive "smart" materials, such as self-repairing and shape-memory gels. ${ }^{4-7}$

PP is a class of polymers mainly consisting of phenylene units, as represented by poly(para-phenylene) (PPP 1, Scheme 1), which are often substituted with solubilizing groups such as bulky alkyl chains and/or additional aryl groups. In the 60 s, Kovacic and Kyriakis investigated the Lewis acid mediated oxidative aryl-aryl coupling of benzenes, forming linear oligo(para-phenylene)s and PPP 1 although with structural defects, limited solubility and low degree of polymerization (DP). ${ }^{8}$ Since then, there have been breakthroughs in the synthesis of various PPs via, for example, metal-catalysed aryl-aryl couplings and cyclotrimerization of alkynes, thermal ring opening of biphenylenes and D-A reactions (vide infra). ${ }^{9-11}$ The topologies of PPs range from the above-mentioned one-dimensional polymers such as PPP $\mathbf{1}$ as molecular "wires" to two-dimensional porous polyphenylenes ${ }^{12}$ and three-dimensional polyphenylene dendrimers. ${ }^{11}$ These PP materials are employed in various applications including organic electronics, sensors, bioimaging and drug delivery. ${ }^{9-11,13-15}$ From an electronic point of view, the benzene rings in PPP $\mathbf{1}$ are twisted away from each other due to the steric repulsion between the protons, which compromises the conjugation along the polymer chain. In 1991, Scherf, Müllen et al. succeeded in "locking" the conformation of a PPP $\mathbf{1}$ by covalently bridging neighboring phenylene rings, leading to a ladder-type poly(para-phenylene)s (LPPP) 2. ${ }^{16}$

Scheme 1. Structures of poly(para-phenylene) 1, ladder-type poly(para-phenylene) 2, angular polyacene ladder-polymer $\mathbf{3}$ and armchair graphene nanoribbon $\mathbf{4}$. Side chains are not shown. 

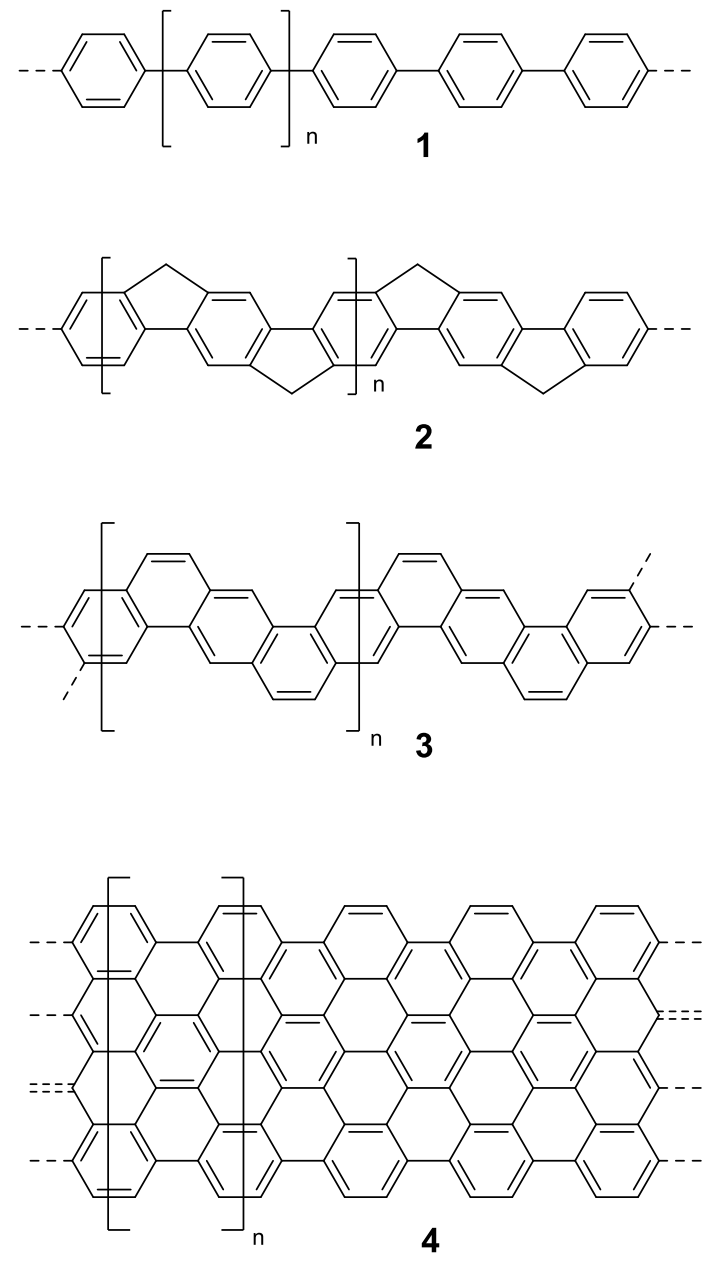

The ladder-polymers can be defined as double-stranded polymers with periodic linkages connecting the two strands, which resemble the rails and rungs of a ladder, ${ }^{17}$ for example, LPPP 2 and the angular polyacene ladder-polymer 3 (Scheme 1). Ladder-polymers can be conventionally constructed through 1) one-pot polymerization, by which the two strands of ladder-polymers are built up simultaneously, for instance by repetitive D-A reactions; and 2) a two-step sequence of polymerization and post-annulation. ${ }^{18}$ In particular, fully conjugated ladder-polymers, including ladder- type PPPs $\mathbf{2}$ and $\mathbf{3}$, are demonstrated to be promising semiconductor materials with outstanding stability, large coherent $\pi$-conjugation length ${ }^{19}$, fast intra-chain charge carrier mobility ${ }^{20}$ and long exciton diffusion length $^{21}$. The remarkable electronic properties of such ladder-polymers make them suitable for applications in the field of organic (opto)electronics such as OLEDs, OFETs and solid-state lasers. ${ }^{18,22-25}$

On the other hand, such fully conjugated ladder-polymers can be regarded as the narrowest examples of graphene nanoribbons (GNRs), quasi-one-dimensional graphene segments with widths smaller than $100 \mathrm{~nm}$ and aspect ratios larger than 10 . 
Granphene is a two-dimensional allotrope of carbon exhibiting excellent electronic properties such as extremely high charge carrier mobility. ${ }^{29}$ Graphene is thus considered as one of the most promising materials for future nanoelectronics. However, the lack of an electronic band gap hinders the application of graphene as a semiconductor material, for example in field-effect transistors. In contrast to the gapless graphene, GNRs, such as armchair GNR 4 (Scheme 1), have tunable band gaps, mainly depending on their width and edge structures, and are emerging as next-generation semiconductor materials. ${ }^{30,31}$ Together with their high intrinsic charge-carrier mobility, GNRs are thus attracting attention for applications in photovoltaic cells, optical sensors and logic gates. ${ }^{32-36}$ In recent years, tremendous progress has been made in the fabrication of GNRs, through top-down and bottom-up approaches. The top-down approach is usually realized by lithographic slicing the graphene sheets and unzipping carbon nanotubes. ${ }^{37-41}$ However, this method provides GNRs with low yield and without structural control. In contrast, the bottom-up protocol offers structurally well-defined GNRs, which is implemented via solution-mediated or surface-assisted planarization of tailor-made polyphenylene precursors by intramolecular cyclodehydrogenation. ${ }^{26,27}$

In this review we shall describe the role of the D-A polymerization in the synthesis of functional PPs (section II), ladder-type polymers (section III) and GNRs (section IV), including the latest updates in the fields. The readers are advised to consult previous reviews in the literature for more comprehensive information about $\mathrm{PPs}^{9-15}$, ladder-type polymers ${ }^{18,22-25}$ and GNRs ${ }^{26-28,30,31,34}$, especially their preparation through other polymerization methods. Here we highlight the key role of the D-A polymerization in the synthesis of these three classes of polymer materials, which are highly related to each other, but have seldom been discussed in a unified view.

\section{Functional polyphenylenes via $D$-A polymerization}

\subsection{The $A_{2} B_{2}$-type $D$ - $A$ polymerization}

The D-A reaction is an obvious protocol for a polymerization reaction to synthesize aromatic polymers, since it generates a six-membered-ring product, which can be aromatized subsequently. However, with its reversible nature, namely the possible retro-D-A reaction of the intermediate products, it is only possible to reach D-A polymers with relatively low degree of polymerization (DP), being limited by the thermodynamics of the reactions. Polymers based on the D-A reactions of furan and maleimide generally possess DP lower than $20 .{ }^{42}$ Nevertheless, it is possible to overcome this obstacle and achieve higher DPs by 1) enhancing the enthalpic driving force for the D-A cycloaddition, typically by the simultaneous aromatization, for example, the D-A reaction of $o$-quinodimethane and $N$-phenylmaleimide ${ }^{43}$ (Scheme 
2a), and/or 2) pre-programming an irreversible consecutive reaction such as removal of a volatile small molecule or aromatization of the D-A adduct. ${ }^{44}$ A representative example is the reaction of 2,3,4,5-tetraphenyl-cyclopentadienone as a diene and diphenylacetylene as a dienophile, leading to the formation of an aromatic benzene ring after removal of carbon monoxide to afford hexaphenylbenzene (Scheme $2 b$, see Table 1 for more specific examples). ${ }^{9,45,46}$

Scheme 2. D-A reaction of (a) o-quinodimethane and $N$-pheylmaleimide, (b) 2,3,4,5-tetraphenylcyclopentadienone and diphenylacetylene.

a.

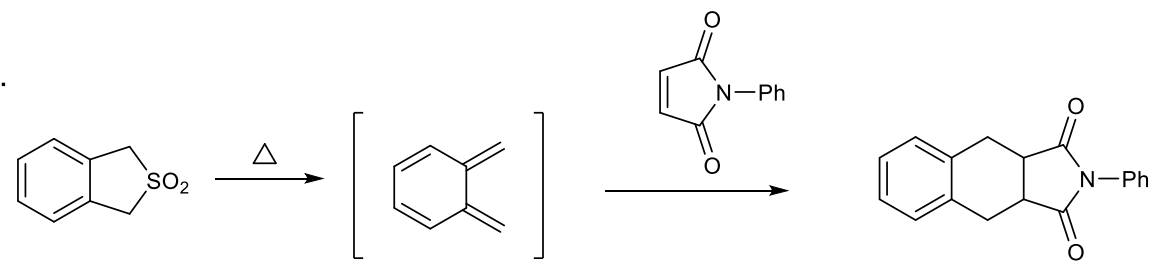

b.

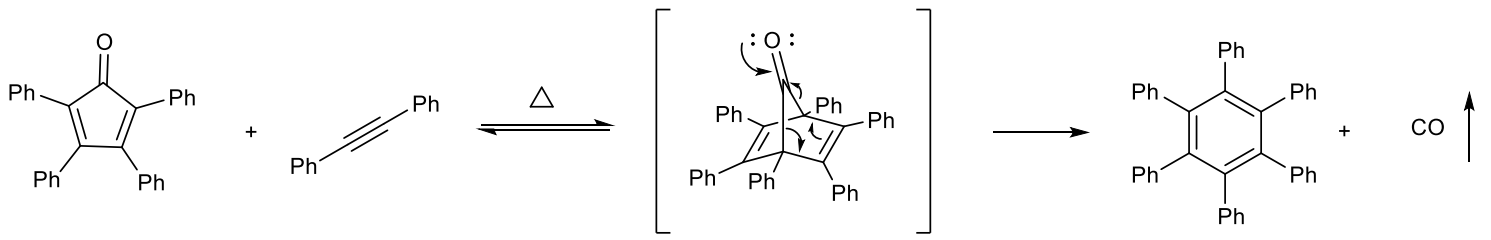

In 1966 Stille et al. developed an $\mathrm{A}_{2} \mathrm{~B}_{2}$-type $\mathrm{D}$-A polymerization using cyclopentadienone ( $\mathrm{Cp}$ ) units as diene for synthesizing phenylated PPs $\mathbf{5}$ and $\mathbf{6}$, where the polymer backbones consisted of random mixtures of para- and meta-phenylenes (Table 1). ${ }^{47}$ The synthesis was accomplished by repetitive D-A reaction of bis-Cps as an $\mathrm{A}_{2}$ monomer and bisacetylene as a $\mathrm{B}_{2}$ monomer in toluene at $300{ }^{\circ} \mathrm{C}$ in a sealed tube, with a possible isomerization upon each cycloaddition step due to the unsymmetrical diene structure of the bis-Cps. In this first attempt, bis-Cps linked with diphenyl (thio)ether or $\alpha, \omega$-diphenyl alkanes were used to react with $m$ - and $p$-diethynylbenzenes (PP 5, with $\mathrm{x}=\mathrm{O}$ or $\mathrm{S}$ and PP 6, with $\mathrm{n}=3$ or 4 for $\mathrm{L}_{1}$, Table 1). In the following few years, the scope of the bis-Cp $\mathrm{A}_{2}$ monomers was extended, while no further progress of using other kinds of bisacetylene had been made (PPs 5-7, Table 1). ${ }^{47-54}$ Table 1 summarizes the different structures of $L_{1}$ and $L_{2}$, the estimated number of monomeric units in the D-A polymer (i.e., degree of polymerization, DP) and thermal decomposition temperature $\left(T_{\mathrm{d}}\right)$ of the representative PPs 5-14 reported in the literature.

Despite the successful demonstration of this $A_{2} B_{2}$-type synthesis of PPs by repetitive D-A reactions, there was no follow-up study on this for about 30 years, probably 
because of the lack of efficient synthetic protocols toward bisacetylenes. ${ }^{55}$ After the booming development of the chemistry of metal-catalysed cross-coupling reactions in the 70s, in particular the Sonogashira-Hagihara coupling, Kumar and Neenan revisited and extended the scope of such D-A polymerizations in $1995 .{ }^{55}$ Bisacetylenes with different $\mathrm{L}_{2}$ such as trimethylsilyl (TMS)- and perfluorobenzene, benzophenone and thiophene were successfully incorporated into this polymerization protocol under milder reaction conditions of heating in cyclohexylbenzene at $200{ }^{\circ} \mathrm{C}$ (PPs 8-11, Table 1).

Table1. Structures of linkers $\mathrm{L}_{1}$ and $\mathrm{L}_{2}$, substituents, degree of polymerization (DP) and decomposition temperature $\left(T_{\mathrm{d}}\right)$ of representative PPs 5-14 synthesized by $\mathrm{A}_{2} \mathrm{~B}_{2}$-type $\mathrm{D}$-A polymerization of bis-Cps and bisacetylenes.

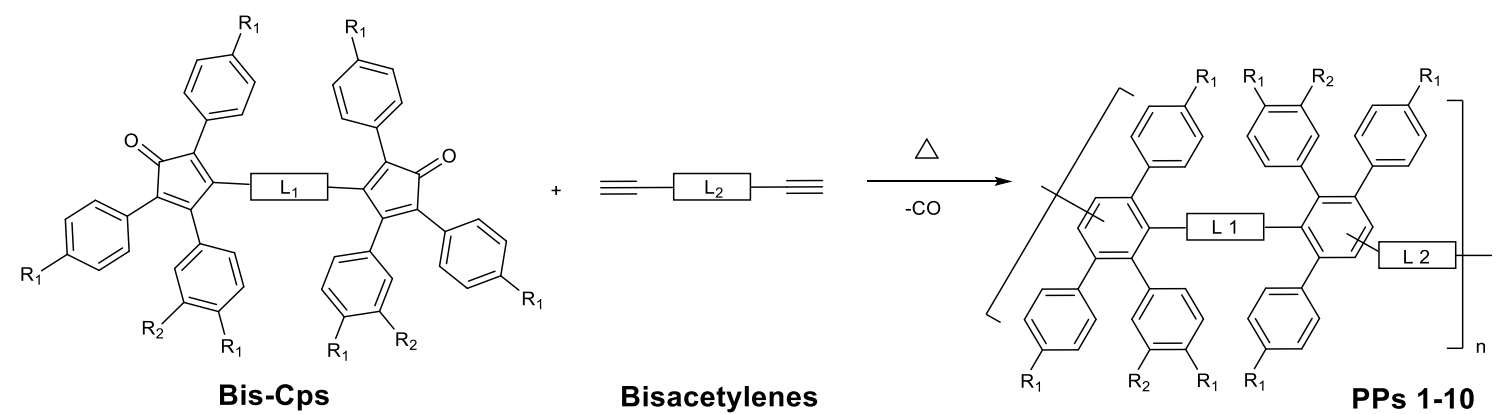

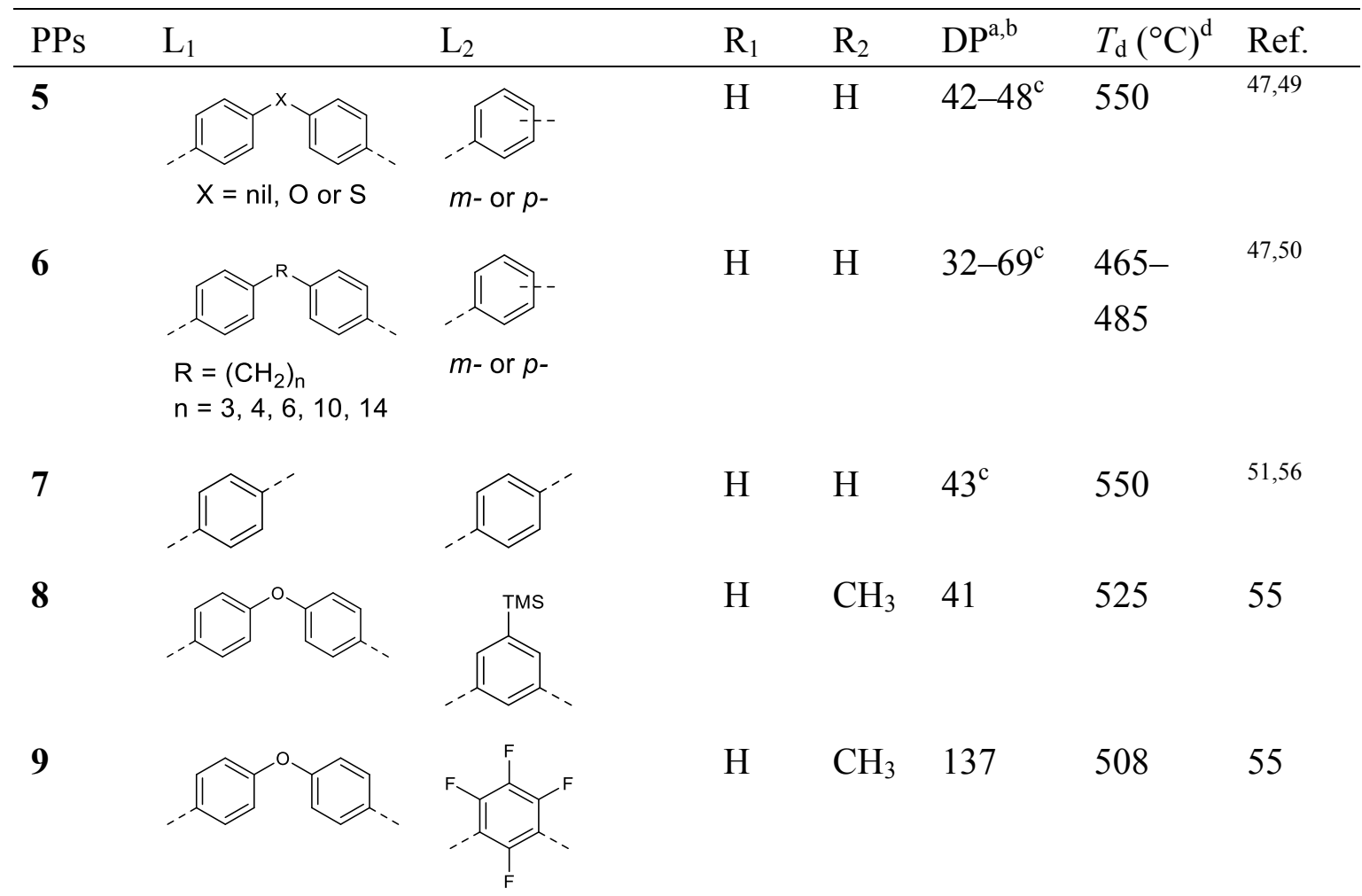


10<smiles>Cc1ccc(Oc2ccc(I)cc2)cc1</smiles><smiles>Cc1ccc(C(=O)c2ccc(I)cc2)cc1</smiles>

11<smiles>Cc1ccc(Oc2ccc(C)cc2)cc1</smiles>

12

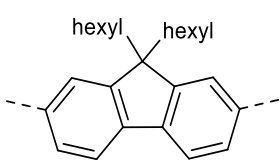<smiles>Cc1ccc(N(c2ccccc2)c2ccc(C)cc2)cc1</smiles>

$\mathrm{H}$

H

400 57

and $^{\mathrm{e}}$

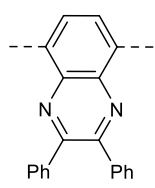

13
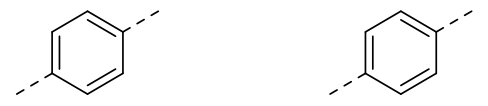

$\mathrm{CH}$

$\mathrm{H}$

365 ,

58

$552^{\mathrm{f}}$

14<smiles>Cc1ccc(C)cc1</smiles>

$\mathrm{H}$

$\mathrm{H} \quad-$

$550^{\mathrm{f}}$

${ }^{\mathrm{a}}$ Determined by gel permission chromatography (GPC). ${ }^{\mathrm{b}}$ The highest reported values are listed. ${ }^{\mathrm{c}}$ Determined by membrane osmometer. ${ }^{\mathrm{d}}$ Determined by thermogravimetric analysis (TGA) measured in air. ${ }^{\text {e}}$ Synthesized as copolymer. ${ }^{\mathrm{f}}$ Temperature of $5 \%$ weight loss.

The highest DP of 137 was obtained when diphenyl ether and tetrafluoro- $m$-phenylene were used as linkers $\mathrm{L}_{1}$ and $\mathrm{L}_{2}$, respectively (PP 5, Table 1). Chromophores such as fluorene, triphenyl amine and quinoxaline could be directly incorporated into the polymer backbone, providing blue emitting materials (PP 12, Table 1). ${ }^{57}$ Moreover, these materials demonstrated very high thermal stability with decomposition temperature $\left(T_{\mathrm{d}}\right)$ up to $550^{\circ} \mathrm{C}$ (Table 1 ). The solubility of these phenylated PPs was surprisingly good in standard organic solvents such as tetrahydrofuran (THF), chloroform, and dimethylformamide (DMF), which could be a result of random meta and para linkages in the polymer backbone established during the polymerization (Table 1). The high DP, stability and solubility rendered such materials attractive for applications as polymer membranes, which require high physical and chemical robustness for the long-term use under harsh conditions. ${ }^{60}$

\subsection{Polymer membrane applications of PPs from $D-A$ polymerization}

\subsubsection{Gas separating membrane}


PPs synthesized via $\mathrm{A}_{2} \mathrm{~B}_{2}$-type $\mathrm{D}$-A polymerization could be cast as films from common organic solvents. ${ }^{47,55}$ The amorphous nature and large fractional free volume of pure hydrocarbon PPs $\mathbf{7}$ and $\mathbf{1 3}$ were revealed by their broad peaks in X-ray scattering patterns, their density and their calculated van der Waals volume, respectively. ${ }^{58}$ These are important requirements for highly permeable membrane applications. ${ }^{61}$ Very recently, Cornelius et al. studied the gas permeability, solubility, diffusivity and selectivity of $\mathrm{He}, \mathrm{H}_{2}, \mathrm{O}_{2}, \mathrm{CO}_{2}, \mathrm{~N}_{2}$, and $\mathrm{CH}_{4}$ gases in membranes composed of PPs 7 and $\mathbf{1 3}$ as well as their copolymers (Table 1). ${ }^{58}$ These membranes displayed cutting edge gas permeability/selectivity trade-off. Namely, they possessed larger $\mathrm{CO}_{2}$ gas permeability (measured as pressure) than those of conventional devices built from polyphenylene oxide and polyimide, while still exhibiting comparable selectivity of $\mathrm{CO}_{2}$ over $\mathrm{N}_{2}$ (20 times larger in permeability).

\subsubsection{Polymer electrolyte membranes}

Polymer electrolyte membranes (PEMs) are showing great potential as components of fuel cells, solar cells, as well as devices for electrolysis, dialysis and water splitting. ${ }^{62,63}$ The standard material used in most cases is Nafion ${ }^{\circledR}$, a poly(tetrafluoroethylene) with pendant perfluorosulfonic acids, possesses low water uptake and high proton conductivity, but suffers from limited operation temperature $\left(0-80{ }^{\circ} \mathrm{C}\right)$, high cost and high fuel cross-over. Hydrocarbon-based polymer electrolytes, due to their synthetic versatility, high chemical stability and relatively low cost, are emerging as an important class of alternative materials for PEMs in electrochemical applications. ${ }^{64}$ Since the first approach conducted by Cornelius and Loy et al. in 2005, a series of hydrocarbon-based PP polyelectrolytes 15-17 were synthesized and investigated. ${ }^{65-69}$ These polyelectrolytes were achieved by sulfonation $^{65,66,68,69}$ or bromination/amination ${ }^{67}$ of phenylated PPs 7, 13 and $\mathbf{1 4}$ subjected to functionalization after initial D-A polymerization (Table 1 and Scheme 3).

Scheme 3. Post-functionalization of PPs 7, 13 and 14 toward hydrocarbon-based polyelectrolyte $\mathbf{1 5 , 1 6}$ and 17. 

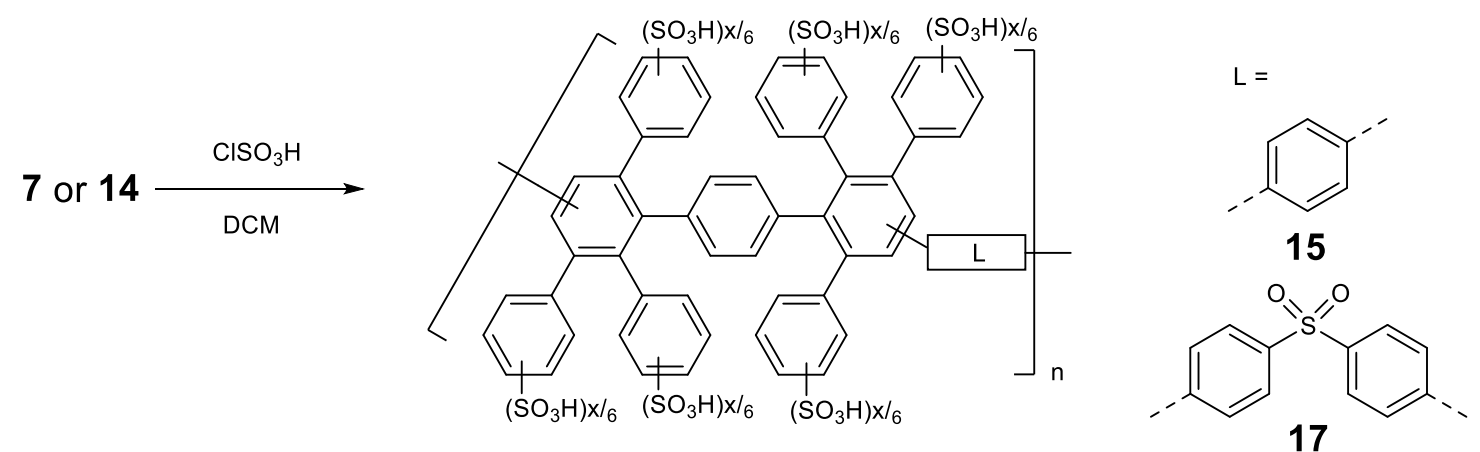

$\mathbf{x}$ depends on IEC

17
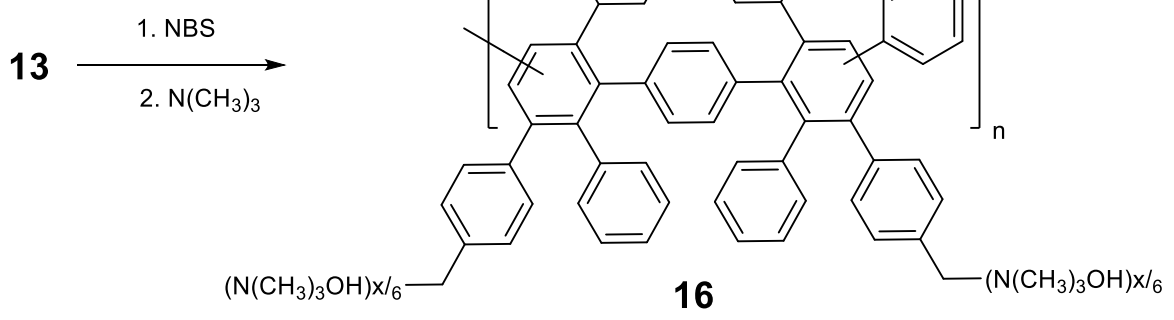

The ion exchange capacity (IEC) of polyelectrolyte 15 varied between 0.98 and 2.2 mequiv/g, corresponding to 0.8-2.1 sulfonic acid groups per repeating unit. These materials were soluble in highly polar aprotic solvent such as dimethylacetamide (DMAc) and $N$-methyl-2-pyrrolidone (NMP) while insoluble in nonpolar organic solvents and water. ${ }^{65}$ They were highly thermally stable with only $5 \%$ weight loss at $363-422{ }^{\circ} \mathrm{C}$ and the glass transition temperature $\left(T_{\mathrm{g}}\right)$ was not observed before the decomposition temperature. In both the dry and wet forms of the membrane of $\mathbf{1 5}$, the Young's modulus was about 6 times higher than that of a commercially available Nafion 117 membrane. ${ }^{65}$ Although the PEM of 15 revealed poorer proton conductivity in comparison with Nafion 117, its methanol and glucose permeability was much smaller. ${ }^{66}$ With these intriguing properties, such PEMs were successfully examined in various applications, including hydrogen/methanol fuel cells ${ }^{68}$, vanadium redox flow battery ${ }^{70}$ and electrodialysis desalination ${ }^{69}$. In particular, the electronic desalination of $1.0 \mathrm{~L}$ of $0.1 \mathrm{wt} \% \mathrm{NaCl}$ using PEM of 15 was completed within $44 \mathrm{~min}$ using $5.8 \mathrm{~J} / \mathrm{g}$, which was much more efficient than the performance of commercially available cation or anion exchange membranes PC-SK and PC-SA. The latter required $8.4 \mathrm{~J} / \mathrm{g}$ and $79 \mathrm{~min}$ for the same volume and concentration of $\mathrm{NaCl}$ solution. ${ }^{69}$

Cornelius et al. also synthesized a cationic polyelectrolyte 16 with the IEC of $0.93-$ 1.57 mequiv./g, through post-bromination/amination of methylated PP 13 (Table 1 and Scheme 3). ${ }^{67}$ Interestingly, the water uptake of this cationic polyelectrolyte 16 
was roughly two times higher than that of its anionic analogue 15 with similar IEC. Noteworthy for an anion exchange membrane, the PEM of 16 exhibited a high hydroxide conductivity up to $50 \mathrm{mS} / \mathrm{cm}$.

In $2014 \mathrm{Kim}$ et al described polyelectrolyte 17, with an IEC of 1.49-2.34 mequi/g, by post-sulfonation of D-A polymerized poly(pentaphenylene sulfone) $\mathbf{1 4}$ (Table 1 and Scheme 3). ${ }^{59}$ The thermal stability of anionic poly(pentaphenylene sulfone) polyelectrolyte 17 was slightly lower than that of PP polyelectrolyte 15 with $5 \%$ weight loss at around $270-350{ }^{\circ} \mathrm{C}$, with superior mechanical properties to those of Nafion 211. Interestingly, the PEM of $\mathbf{1 7}$ showed a lower water uptake in comparison with that of 15 , probably a result of selective sulfonation on the pendant phenyl rings due to the lowered reactivity of the phenylene backbone in the presence of electron withdrawing sulfone groups. The PEM of 17 with IEC of 2.34 mequi/g provided a higher proton conductivity than that of Nafion 212 , leading to a slightly more efficient hydrogen fuel cell.

Holdcroft and co-workers reported the synthesis of polyelectrolytes 19a-c by D-A polymerization of pre-sulfonated 4,4'-(1,4-phenylene)bis-(2,3,5-triphenylcyclopenta-2,4-dien-1-one) 18 with 1,4-diethynylbenzene, 4,4'-diethynylbiphenyl and 1,4-diethynylnaphthalene, respectively (Scheme 4). This approach achieved precise numbers of functionalization at specific positions, in contrast to PPs 15-17 prepared through the rather random post-sulfonation. ${ }^{71,72}$ With very high DP of up to 125 and PDI of 1.44-2.33, polymers 15a-c displayed good mechanical strength and thermal stability similar to those of their analogues $\mathbf{1 5}$ and $\mathbf{1 7}$. The IEC of polyelectrolyte 19a-c was as high as $3.47,3.19$ and 3.28 mequiv/g, respectively.

Scheme 4. D-A polymerization of pre-sulfonated 4,4'-(1,4-phenylene)bis(2,3,5-triphenylcyclopenta-2,4-dien-1-one) monomer $\mathbf{1 8}$ toward polyelectrolyte 19a-c
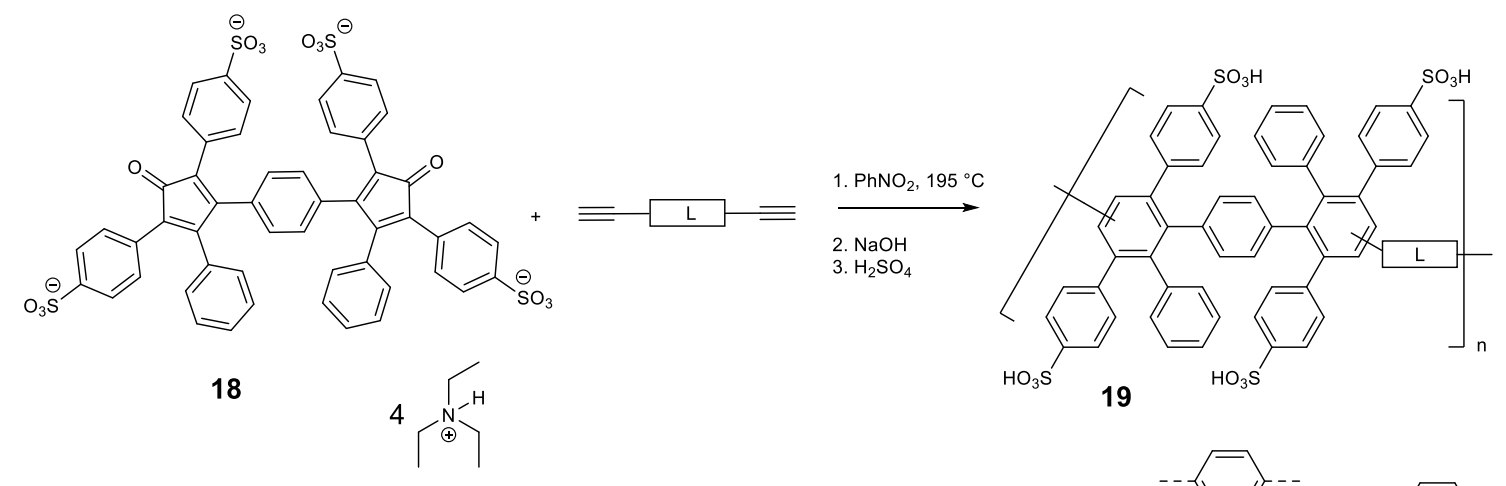

$L=$

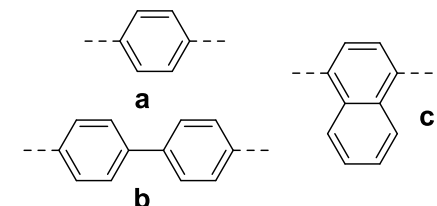


With the larger hydrophobic bridges, the water uptake of biphenylene and naphthylene-spaced 19b and 19c was smaller than that of phenylene-spaced 19a although still much larger (about 6 and 9 times, respectively) than that of Nafion 211. Nevertheless, the remarkably high proton conductivity of the PEM of $19 b$ and 19c (172 and $268 \mathrm{mS} / \mathrm{cm}$, respectively, compared with $113 \mathrm{mS} / \mathrm{cm}$ of the PEM of Nafion 211 at $95 \%$ relative humidity, $80{ }^{\circ} \mathrm{C}$ ) furnished a remarkable performance of their hydrogen fuel cells. The hydrogen fuel cells of $19 \mathrm{~b}$ and 19c exhibited a $56 \%$ and $17 \%$, respectively, greater peak power density than that of Nafion 211. Moreover, the durability of the hydrogen fuel cell using biphenylene-spaced $19 \mathrm{~b}$ as membrane material was more than 4 times longer than that of Nafion 211.

The hydrocarbon-based D-A phenylated PPs PEMs with their superior chemical and thermal stability as well as mechanical strength could reach comparable and even higher performances than that of the most commonly used Nafion-based PEMs. Clearly, they are thus possible candidates for future PEM applications.

\subsection{Hyperbranched polyphenylene by $D$-A polymerization}

In contrast to the time-consuming step-by-step synthesis of a dendrimer from $\mathrm{AB}_{\mathrm{n}}$ building blocks ${ }^{11,14,15}$, hyperbranched polymers could be constructed in a one-pot "uncontrolled" polymerization of, in principle the same, but unprotected $\mathrm{AB}_{\mathrm{n}}$-type monomers, ideally forming a branch on every repeating unit. Molecularly defined dendrimers as well as dendritic and hyperbranched polymers establish a class of attractive materials in view of their unique properties derived from their branched 3D architectures, such as the possibility to accommodate a large number of functional groups, high solubility and low viscosity. ${ }^{73}$ PPs synthesized by repetitive D-A reaction can furnish highly substituted benzene building blocks whose molecular weights are higher than those achieved by other methods such as cross-coupling reactions. ${ }^{9}$ This makes the D-A reaction a very promising choice for the synthesis of hyperbranched phenylated PPs.

In parallel with the development of polyphenylene dendrimers from $\mathrm{AB}_{2}$-type 3,4-bis(4-ethynylphenyl)-2,5-diphenylcyclopentadienone-based building blocks 20 , we have also worked on direct D-A polymerization of monomers 20a-c to form hyperbranched phenylated PPs with DP of around 45 and PDI of 1.7-6.9 (Scheme 5). ${ }^{74}$ The resulting polymers exhibited high thermal stability with $T_{\mathrm{d}}$ higher than 550

${ }^{\circ} \mathrm{C}$ and good solubility in toluene and benzene even without solubilizing substituents. To test the possibility of forming free-standing tubular structures of such hyperbranched polymeric materials, monomer 20d with long alkyl chains was D-A polymerized in a vertically nanochanneled aluminum membrane template at above $200{ }^{\circ} \mathrm{C}$ (Scheme 5). ${ }^{75}$ After removal of the template the resulting material formed 
highly flexible and orderly aligned hollow nanotubes. They possessed a wall thickness ranging from 5 to $50 \mathrm{~nm}$, an average diameter of $200 \mathrm{~nm}$ and a length up to $60 \mu \mathrm{m}$, corresponding to the thickness of the aluminum membrane used as template (Figure 1a). Moreover, it was possible to form a highly porous carbon nanotube through direct carbonization of the hyperbrached polymer in the aluminum membrane by heating to $600{ }^{\circ} \mathrm{C}$, followed by removal of the template (Figure $1 \mathrm{~b}$ ). The pore size was large and up to $20 \mathrm{~nm}$, which probably stemmed from cleavage of the alkyl chains of $\mathbf{2 0 d}$ during the carbonization.

Scheme 5. Structures of $\mathrm{AB}_{2^{-}}, \mathrm{AB}-$ and $\mathrm{A}_{2}$-type tetraphenylcyclopentadienone-based monomers and $\mathrm{B}_{3^{-}}, \mathrm{B}_{6}$-type multiacetylene monomers as building blocks for hyperbranched PPs.
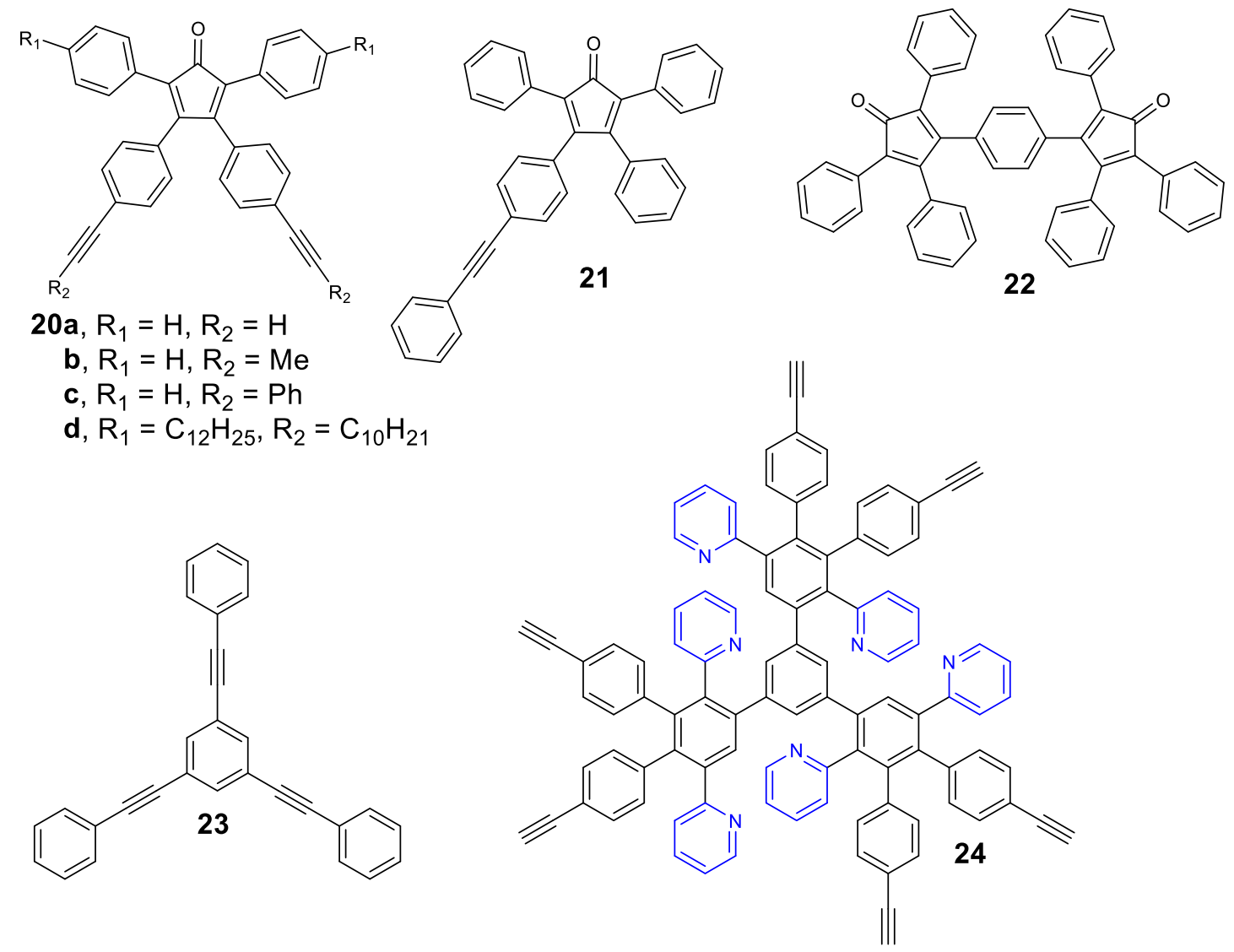

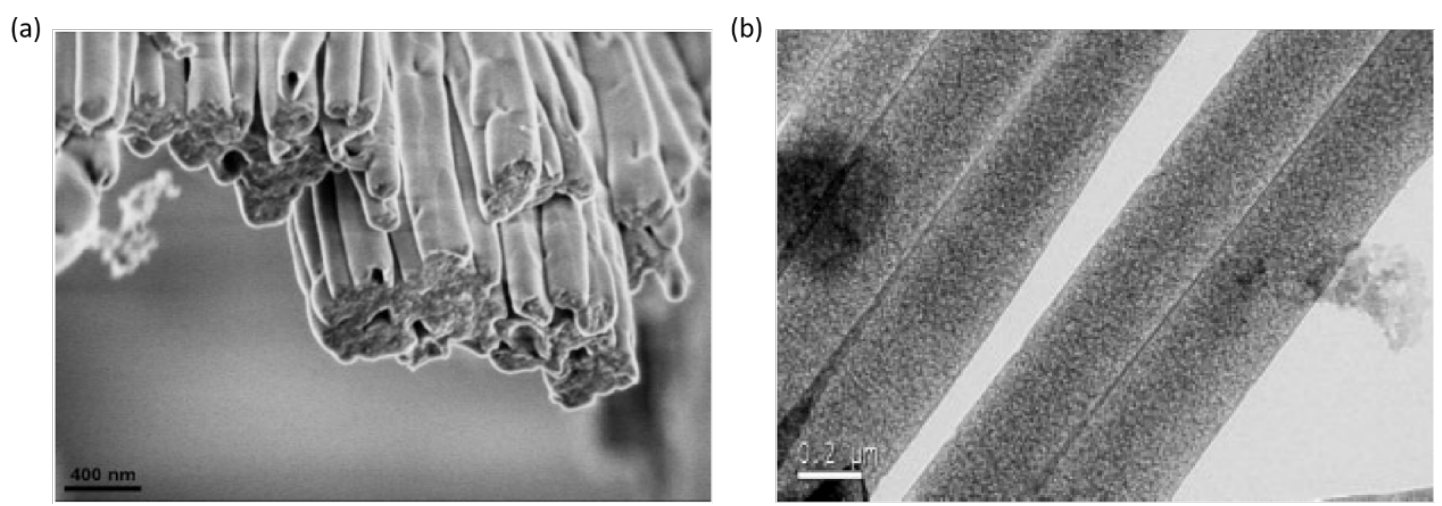

Figure 1. SEM images of (a) hyperbranched PPs nanotubes of 20d and (b) after pyrolysis at $600{ }^{\circ} \mathrm{C}$. Reprinted with permission from Ref 75. Copyright 2005 John Wiley \& Sons.

Voit et al. revisited this field and developed two more hyperbranched PP systems in 2006, namely through 1) an $A B+A_{2}$-type D-A polymerization of $20 \mathrm{c}\left(\mathrm{AB}_{2}\right)$ and 21 $(A B)$, extending the above-mentioned $A_{2}$ system from 20, and 2) an $A_{2} B_{3}$-type D-A polymerization of 4,4'-(1,4-phenylene)bis(2,3,5-triphenylcyclopenta-2,4-dien-1-one) (22) $\left(\mathrm{A}_{2}\right)$ and 1,3,5-tris(phenylethynyl)benzene $(\mathbf{2 3})\left(\mathrm{B}_{3}\right)$, related to the $\mathrm{A}_{2} \mathrm{~B}_{2}$ systems described in sections 2.1 and 2.2 (Scheme 5). ${ }^{76} \mathrm{~A} M_{\mathrm{w}}$ as high as $74 \mathrm{~kg} / \mathrm{mol}$ was achieved for the $A B+A B_{2}$ system when the reaction was carried out at a ratio of $3: 1$ for 20c $\left(A_{2}\right)$ and $21(A B)$. The more $A B$ linear segments 21 were used, the lower the resulting molecular weight became. On the other hand, the molecular weight of the $\mathrm{A}_{2} \mathrm{~B}_{3}$ polymers was lower than those of the previous $\mathrm{AB}_{2}$ polymers. The NMR spectral analysis suggested that in this $\mathrm{A}_{2} \mathrm{~B}_{3}$ system the formation of the linear polymer was favored. The third $\mathrm{B}$ unit in $\mathrm{B}_{3}$ monomer $\mathbf{2 3}$ would react only when using a large excess of $\mathrm{A}_{2}$ monomer 22, thus opening a way to control the degree of branching of the resulting polymers.

Along the same lines, Shifrina et al. described hyperbranched pyridylphenylene polymers based on $\mathrm{A}_{2} \mathrm{~B}_{6}$-type D-A polymerization of $22\left(\mathrm{~A}_{2}\right)$ and $24\left(\mathrm{~B}_{6}\right)$ (Scheme 5). ${ }^{77}$ Gelation was observed when the reactions were carried out at a $3: 1$ ratio of $A_{2}$ (22) and $\mathrm{B}_{6}(\mathbf{2 4})$ monomers, probably because of severe cross-linking occurring at this exact stoichiometric ratio of $\mathrm{A}$ and $\mathrm{B}$ units. The detectable highest $M_{\mathrm{w}}$ of $80 \mathrm{~kg} / \mathrm{mol}$ was achieved when using a 1:1 ratio of $\mathrm{A}_{2}(\mathbf{2 2})$ and $\mathrm{B}_{6}(\mathbf{2 4})$ building blocks. Based on NMR spectra, the degree of branching of this $\mathrm{A}_{2} \mathrm{~B}_{6}$ system could be controlled. By adjustment of the stoichiometry of $\mathrm{A}$ and $\mathrm{B}$ units, dominantly three- to five-fold reaction of the $\mathrm{B}_{6}$ building blocks could be achieved.

These hyperbrached PPs achieved by D-A polymerization featured high molecular weight and controllable degrees of branching and also offered the possibility of 
introducing high numbers of functional groups. This new class of functionalized PPs would be intriguing for future applications for example in the PEM materials mentioned in section 2.2.

\section{Ladder-polymers synthesized by $D$-A reactions}

The D-A reactions have a historical importance for the development of ladder-polymers. With the concerted mechanism of D-A reactions, the two strands of ladder-polymer could be built up simultaneously. This efficiently reduces the possibility of side reactions, which is a great advantage for the synthesis of defect-free ladder-polymers. As early as in 1962 Bailey et al. reported the synthesis of ladder-polymer 28 from one of the simplest bisdienes, 2-vinylbutadiene (25) by D-A polymerization (Scheme 6$)^{78}$

Scheme 6. Synthesis of the first D-A ladder-polymer 28.<smiles>C=CC(=C)C=C</smiles>

25<smiles>O=C1C=CC(=O)C=C1</smiles>

26

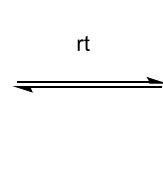

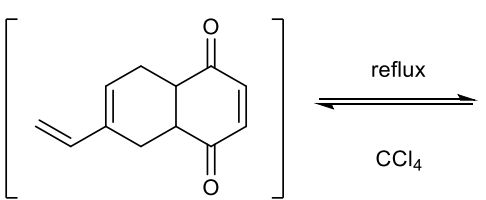

27

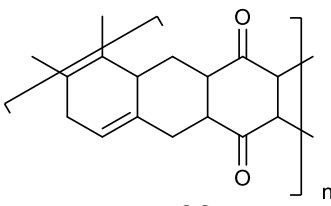

28

The D-A reaction between bisdiene 25 and $p$-benzoquinone (26) at room temperature probably formed the 1:1 adduct 27 , which had both diene and dienophile moieties. Thus, 27 further homopolymerized as an AB-type monomer in a refluxing $\mathrm{CCl}_{4}$ solution to afford ladder-polymer 28. Unfortunately, the resulting structure $\mathbf{2 8}$ could barely be dissolved in hot chlorinated organic solvents and the soluble part was a mixture mainly containing dimer and trimer.

After this example, several successful D-A polymerization systems have been applied for the synthesis of ladder-polymers possessing rigid and semi-rigid structures. In the following sections these products will be categorized by the different bisdienes used in their synthesis.

\subsection{Monomers containing 1,2,5,6-tetramethylenecyclooctane and} 1,2,4,5-tetramethylenecyclohexane structures, toward synthesis of rigid and semi-flexible ladder-polymers

Tetramethylenecycloalkanes, with rigid and bended structures like $\mathbf{2 9}$ or more flexible cyclooctadiene structures like $\mathbf{3 0}$ and $\mathbf{3 1}$, can react as a bisdiene and form ladder-polymers with unprecedented architectures (Scheme 7). In 1987 Stoddart and Williams et al. synthesized a cyclic "molecular belt" from two 
2,3,5,6-tetramethylene-7-oxabicyclo[2.2.1]heptanes (29a) and two 1,4,5,8-tetrahydro1,4:5,8-diepoxyanthracenes (32) by $\mathrm{A}_{2} \mathrm{~B}_{2}$ type $\mathrm{D}$-A reaction under high-pressure conditions, which became possible by the rigid bended structures of 29a and 32 as well as the high stereoselectivity of the D-A reaction. ${ }^{79}$ We used similar bisdiene $29 \mathbf{b}$ and bisalkene 33 to construct ladder-polymer $34 .^{80,81}$ In our approach a 1:1 mixture of the $s y n$-isomer of bisalkene $\mathbf{3 3}$ and its anti-isomer that would form a more extended D-A adduct were used to supress the possible formation of small cyclic products. The $\mathrm{A}_{2} \mathrm{~B}_{2}$ type D-A polymerization of $\mathbf{2 9 b}$ and $\mathbf{3 3}$ was achieved in dichloromethane at 65 ${ }^{\circ} \mathrm{C}$ under high pressure of $7.5 \mathrm{kbar}$. The obtained polyacene precursor 34 was soluble in common organic solvents such as THF and acetone with DP up to 17 and PDI of 2.8-3.2. The thermal stability of this polymer was low with $T_{\mathrm{d}}$ at around $\mathrm{C}_{6} \mathrm{H}_{13} 200{ }^{\circ} \mathrm{C}$.
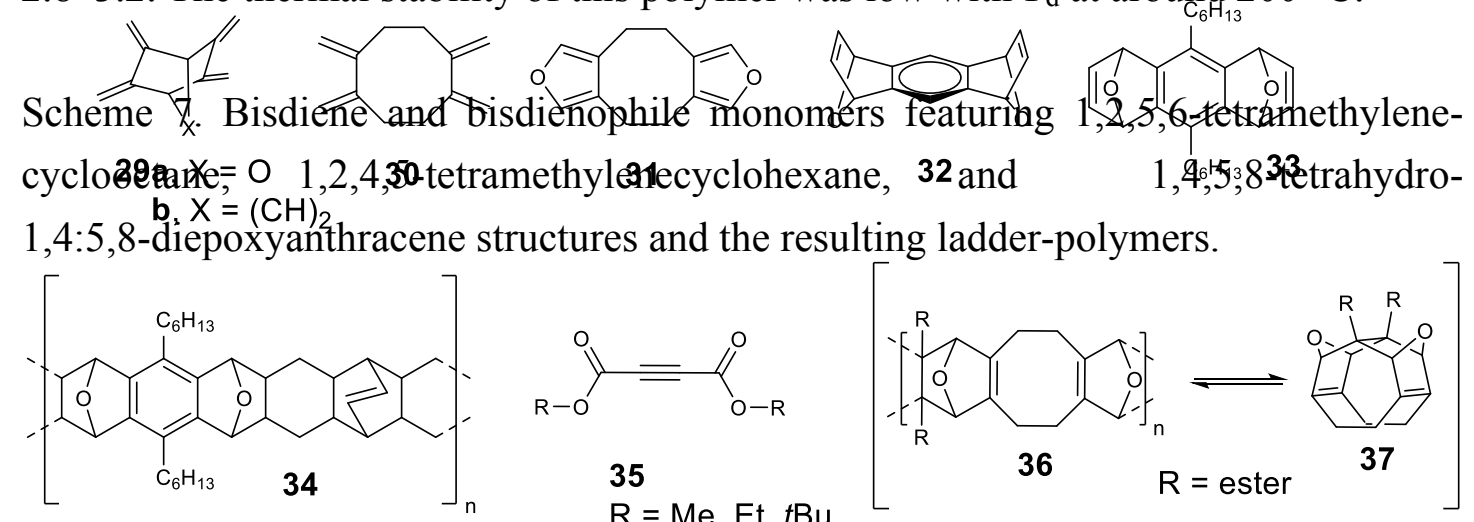

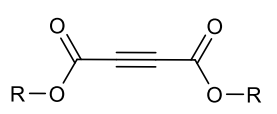

35

$\mathrm{R}=\mathrm{Me}, \mathrm{Et}, \mathrm{tBu}$,

$\mathrm{C}_{8} \mathrm{H}_{17}, \mathrm{C}_{2} \mathrm{H}_{4} \mathrm{OMe}$

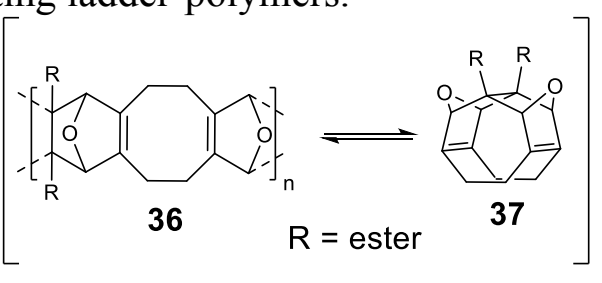

In addition, we also examined monomers $\mathbf{3 0}$ and $\mathbf{3 1}$ featuring 1,2,5,6-tetramethylenecyclooctane structures and found that the reactivity of $\mathbf{3 1}$ toward D-A polymerization was higher than that of $\mathbf{3 0}$ (Scheme 7). ${ }^{82}$ The D-A adducts of monomers $\mathbf{3 0}$ and $\mathbf{3 1}$ contain a semi-flexible cyclooctadiene moiety as "molecular hinge" which can adopt chair, boat and twist-boat conformations. This gave the D-A ladder-polymers built from bisdiene $\mathbf{3 0}$ or $\mathbf{3 1}$ a higher degree of conformational freedom than those built from rigid bisdiene 29. The $\mathrm{A}_{2} \mathrm{~B}_{2}$-type $\mathrm{D}$-A polymerization of bisdiene $\mathbf{3 1}$ and alkyne $\mathbf{3 5}$ (reacted as an equivalent of bisalkene) under high pressure $(8 \mathrm{kbar})$ resulted in a complicated dynamic equilibrium, where linear ladder-polymer 36 could be isolated in $80 \%$ yield at $100{ }^{\circ} \mathrm{C}$ with the highest DP of 27 (Scheme 7). ${ }^{83}$ On the other hand, at $50{ }^{\circ} \mathrm{C}, 1+1$ cyclic cage product 37 together with other larger cyclic compounds were favored with up to $60 \%$ isolated yield. 
3.2 Monomers containing cyclopentadienone moieties, toward synthesis of fully conjugated ladder-type polyfluoranthene

The use of cyclopentadienone as diene for the synthesis of fully conjugated ladder-polymers was first tackled by Stille et al. in $1970 .{ }^{84}$ In this approach, the AB-type cyclopentadienone-based monomer 38 with phenyl side groups was D-A polymerized and in-situ aromatized by air to afford ladder-type polyfluoranthene $\mathbf{3 9}$, featuring a similar structure as the belt region of $\mathrm{C}_{60}$ (Scheme 8). Ladder-polymer 39 with a fully conjugated aromatic structure could also be considered as the first synthesized GNR with defined defects. Polyfluoranthene 39 was thermally stable with $10 \%$ weight loss at around $400{ }^{\circ} \mathrm{C}$. However, it displayed very low solubility and could be only partially dissolved in benzene. Schlüter and Löffler et al. tackled the solubility and characterization problem of ladder-polymer 39 in 1994 by replacing the phenyl side groups with bridged flexible alkyl chains as well as isolating non-aromatized polymer precursor $41 .{ }^{85}$ Addition of an antioxidant during D-A polymerization of AB-type monomer $\mathbf{4 0}$ successfully hindered the otherwise simultaneous aromatization and allowed isolating ladder-polymer $\mathbf{4 1}$. The nonplanar structure and bridged alkyl chains of $\mathbf{4 1}$ rendered it well soluble in THF and chloroform. Polymer 41 was thus characterized by ${ }^{1} \mathrm{H},{ }^{13} \mathrm{C}$ NMR, UV-VIS spectra and gel permission chromatography (GPC) to reveal its DP and PDI of 7-14 and 2.5-2.8, respectively. The planarization of polymer precursor 41 toward fully conjugated fluoranthene ladder-polymer $\mathbf{4 2}$ was achieved by oxidation in the presence of DDQ, demonstrating an optical absorption of oligomers extending up to ca. $600 \mathrm{~nm}$. Nevertheless, the high-molecular-weight fraction of $\mathbf{4 2}$ still gave low solubility in common organic solvents such as THF and chloroform.

Scheme 8. Synthesis of fully conjugated fluoranthene ladder-polymers 39 and $\mathbf{4 2}$ by D-A polymerization of AB-type monomers 38 and $\mathbf{4 0}$, respectively. 


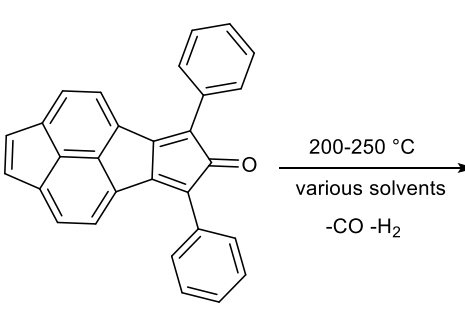

38

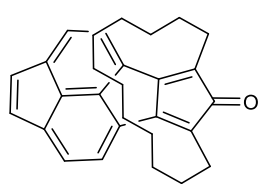

40

toluene, reflux

antioxidant

$-\mathrm{CO}-\mathrm{H}_{2}$
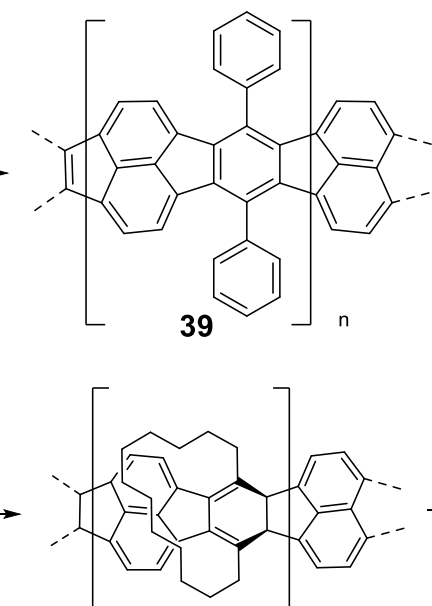

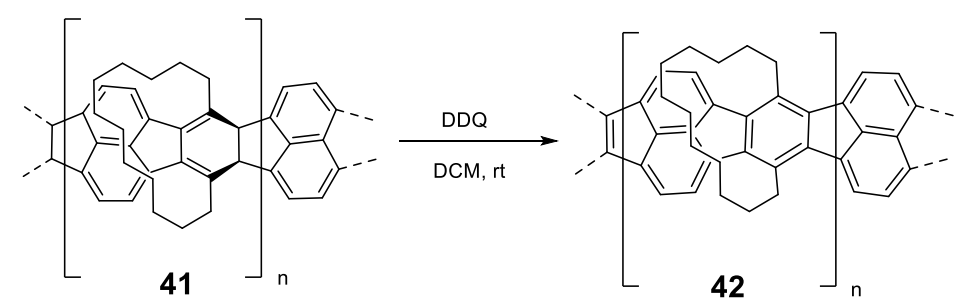

3.3 In-situ generation of benzo[1,2-c:4,5-c']difuran as bisdiene for the synthesis of fully conjugated ladder-polymers

In parallel with the synthesis of fully conjugated ladder-polymers using cyclopentadienone containing monomers, Schlüter et al. developed another method utilizing highly reactive benzo[1,2-c:4,5-c']difuran 44 to react with bisalkene 33,45 and 46 for the synthesis of ladder-polymers 47,48 and 49, respectively, via D-A polymerization (Schemes 7, 9 and 10). ${ }^{86-88}$ The bisdiene 44 with its open-shell biradical character was very unstable and extremely reactive, and could not be isolated. However, Hart and Luo discovered that by heating of pentacene anologue $\mathbf{4 3}$ above $190{ }^{\circ} \mathrm{C}$, it was possible to in-situ generate 44 via two-fold retro-D-A reaction (Scheme 9), which could then be reacted with another dienophile. ${ }^{89}$

Scheme 9. In-situ generation of reactive benzo[1,2-c:4,5-c']difuran 44.

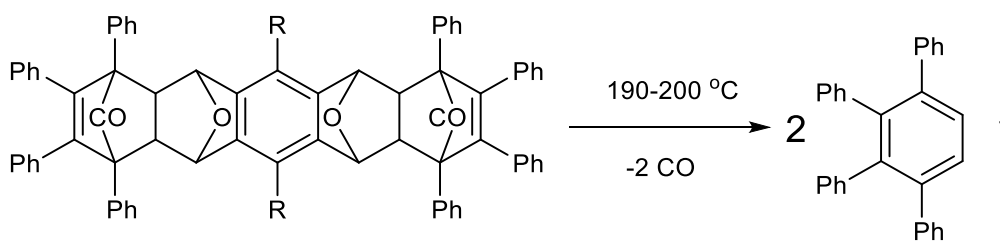

43<smiles>[R]C1c2cocc2C(C)c2cocc21</smiles>

$44 a, R=H$

b, $\mathrm{R}=\mathrm{C}_{6} \mathrm{H}_{13}$

c, $\mathrm{R}=\mathrm{C}_{12} \mathrm{H}_{25}$

The synthetic design of ladder-polymers using $\mathbf{4 4}$ was similar to that of polymer $\mathbf{4 2}$. D-A polymerization was thus used for the one-pot construction of soluble kinked polymer precursors, which could be processed from solution, characterized and further "planarized" into fully conjugated ladder-polymers. For example, D-A polymerization of bisdiene 44a with phenacene 45a provided ladder-polymer 47a that featured separate acene-like and phenacene segments, although with poor solubility. 
In contrast, use of bisdienophile $\mathbf{4 4 b}$ with longer alkyl side chains afforded ladder-polymer $\mathbf{4 7 b}$, which exhibited sufficient solubility for further characterizations. Its DP was estimated as $7 .{ }^{86}$ On the other hand, the soluble polyacene precursor 48 was synthesized from the D-A polymerization of $\mathbf{3 3}$ with in-situ generated $\mathbf{4 4 b}$, reaching a DP of 23. Thermogravimetric analysis (TGA) suggested that polymer $\mathbf{4 8}$ was stable until $300{ }^{\circ} \mathrm{C} .{ }^{87}$ However, planarization of polymers $\mathbf{4 7}$ and $\mathbf{4 8}$ toward fully conjugated ladder-polymers has not been reported. With the same bridged alkyl chains as polymer 42, another "polyacene-like" ladder-polymer 49 was synthesized by D-A polymerization of $\mathbf{4 4 b}$ with bisdienophile $46 .{ }^{88}$ The soluble fraction of ladder-polymer 49 gave a DP up to 7 while about $70 \%$ of the product was insoluble. Further dehydration of the obtained polymer precursor 49 under acidic conditions yielded a barely soluble material, which ideally would possess the fully conjugated structure 50. The UV-VIS absorption of the soluble fraction of this product extended to over $650 \mathrm{~nm}$, which suggested the formation of a low-defect ladder-polymer with extended conjugation although the unambiguous elucidation of the structure as $\mathbf{5 0}$ remained elusive. ${ }^{88}$

Scheme 10. Ladder-polymers 47, 48, 49 and 50 synthesized through D-A polymerization using benzo[1,2-c:4,5-c']difuran.

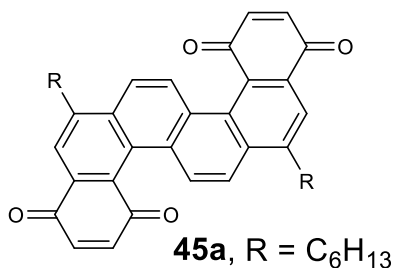

b, $\mathrm{R}=\mathrm{C}_{12} \mathrm{H}_{25}$

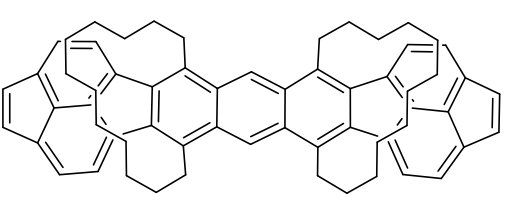

46

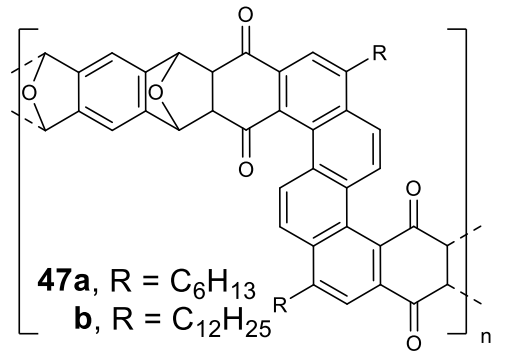

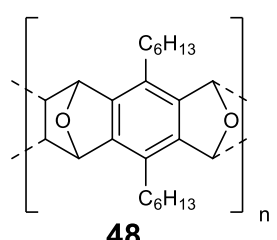
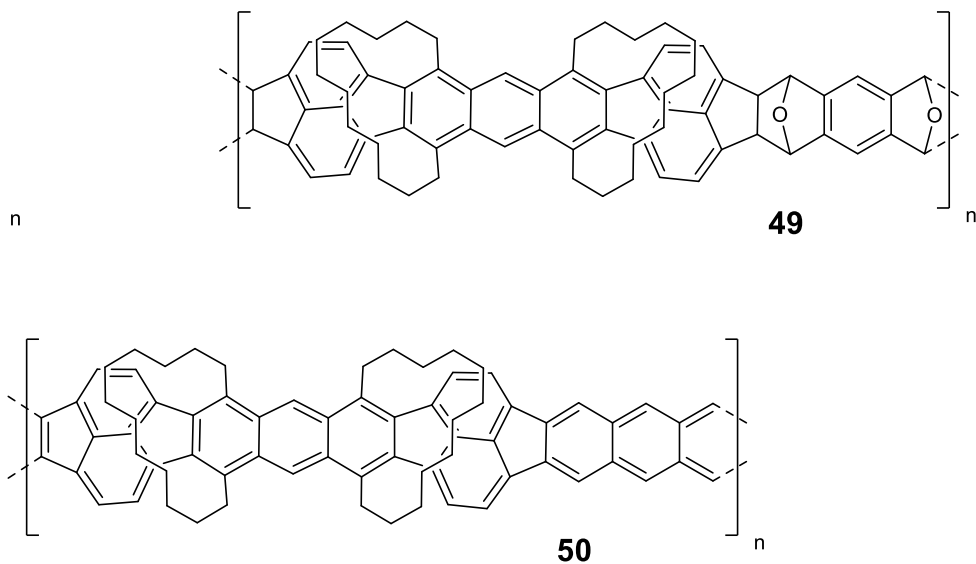

3.4 Anthracene as the diene to provide poly(iptycene)s 
Iptycene is a class of aromatic compounds composed of bicyclooctatriene-brighed arenes. The simplest example is triptycene 51 (Scheme 11). The incorporation of iptycenes into poly(p-phenyleneethynylene) could enhance its solubility and mechanical properties. ${ }^{90}$ Iptycenes are often synthesized from D-A reactions of anthracenes and higher acenes with dienophiles. ${ }^{91}$ Swager et al. synthesized ladder-type poly(iptycene) $\mathbf{5 4}$ via D-A polymerization of AB-type iptycene monomer 51, containing anthracene moieties (Scheme 11). ${ }^{92,93}$ Polymerization of 51 in refluxing decaline failed, but polymerization occurred when the reaction was carried out under $8.9 \mathrm{kbar}$ to afford 54. Addition of a $5 \mathrm{~mol} \%$ of $\mathrm{A}_{2}$ and $\mathrm{B}_{3}$ cross-linkers 52 and 53, respectively, increased the DP from 19 to 60. When polymer 54 was dispersed in uniaxially stretch-aligned polyvinyl chloride (PVC) thin films, it tended to align such that the short axes of the anthracene (end)groups were parallel to the stretching direction, as illustrated in Figure 2. Taking into account that anthracene itself prefers to align with its long axis parallel to the stretching direction, this behavior of poly(iptycene) $\mathbf{5 4}$ was controlled by the rigid linear nonplanar architecture granted by unique iptycene building blocks in the backbone. The perpendicular packing of the backbone of poly(iptycene) $\mathbf{5 4}$ and PVC chains hardly perturbed the anisotropic alignment of the PVC polymer matrix. This largely reduced the local PVC density change and the force applied on poly(iptycene) chains upon stretching (Figure 2).

Scheme 11. Structures of iptycene-containing ladder-polymers and the monomers from which they were derived.

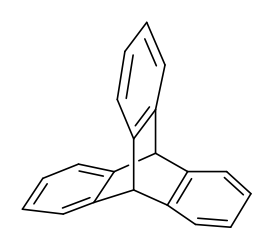

51

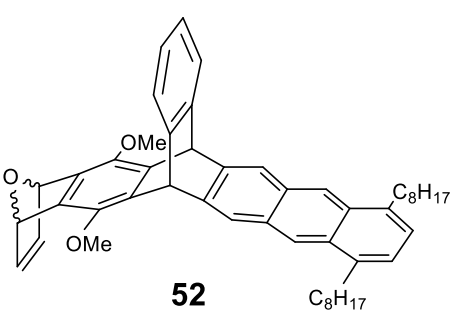

52
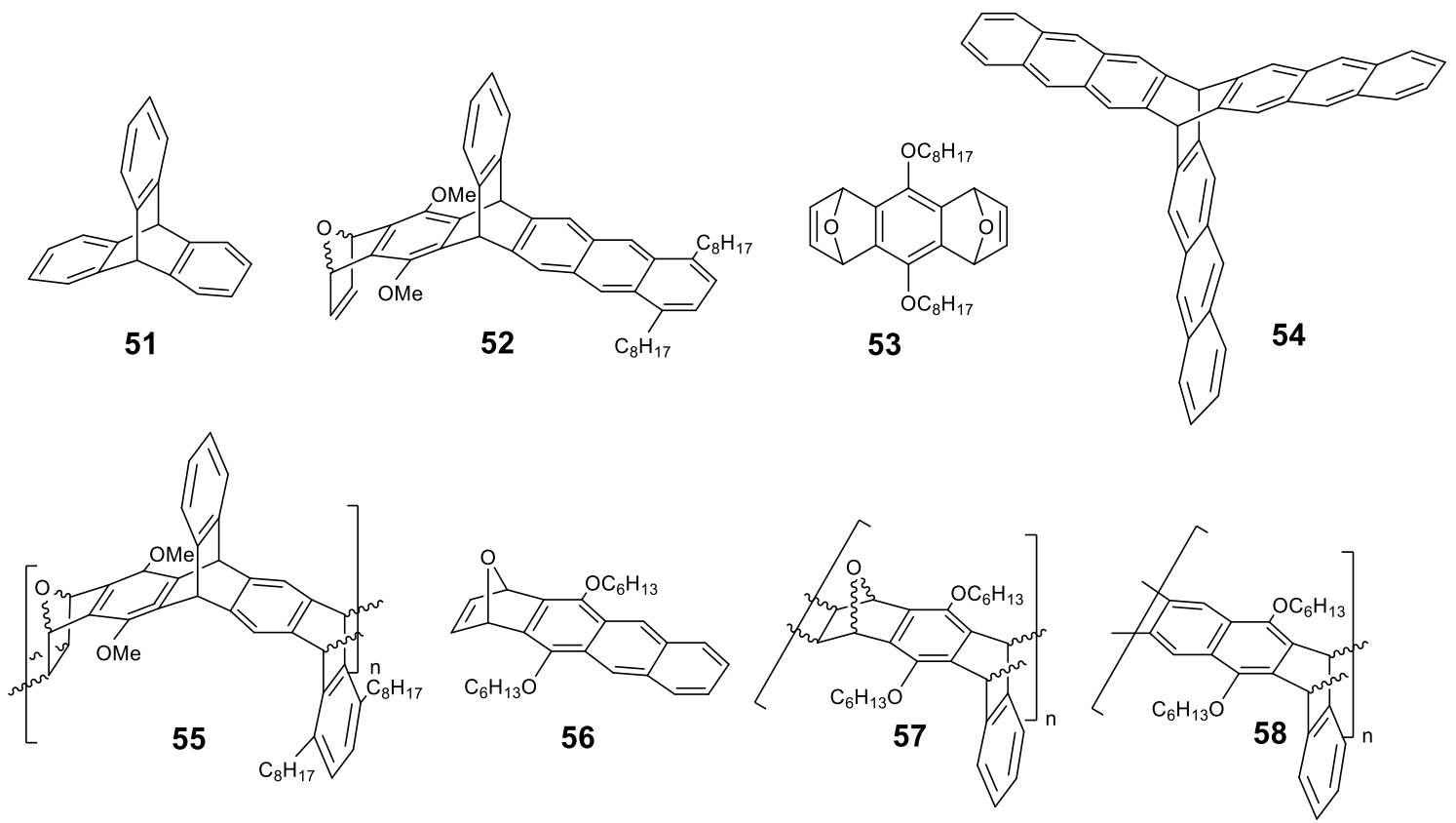


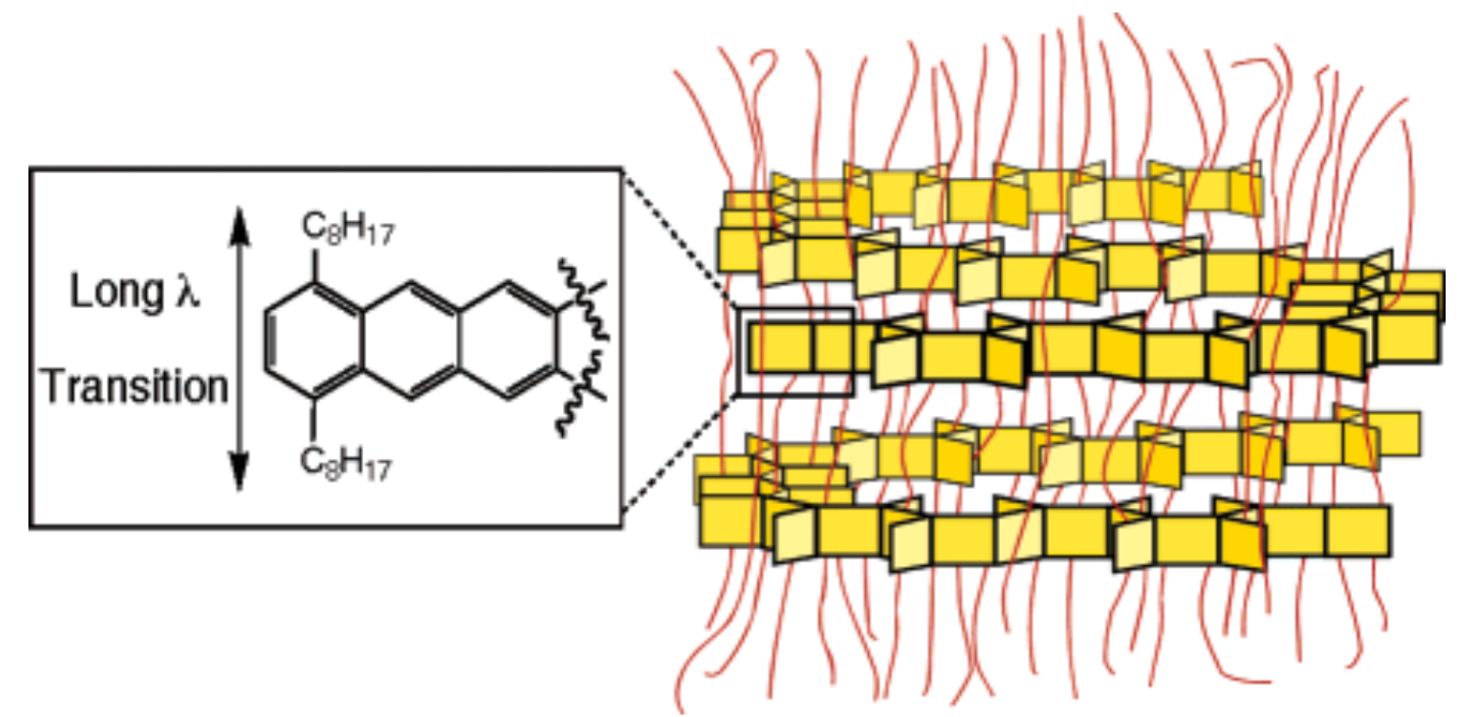

Figure 2. Schematic illustration of stretch-aligned PVC threaded through polymer $\mathbf{5 4}$ and the resulting perpendicular orientation of the two polymers. Reprint with permission from Ref 92. Copyright 2005 American Chemical Society.

Swager et al. also reported AB-type monomer 54 without preinstalled iptycene structure, which was first thermally examined by DSC and TGA, revealing that the polymerization took place at around $162-215^{\circ} \mathrm{C}$ to afford poly(iptycene) precursor 56. The DP up to 40 and PDI of 2.2-3.6 of $\mathbf{5 6}$ could be achieved when the polymerization was performed at $10 \mathrm{kbar}$ in THF at $145{ }^{\circ} \mathrm{C}$. Poly(iptycene) precursor 56 was soluble in DCM, chloroform and THF, which allowed complete dehydration in acidic conditions to form poly(iptycene) $\mathbf{5 7}$, which was thermally stable up to $350{ }^{\circ} \mathrm{C}$. With the alkoxy side chains and iptycene structures in the backbone, ladder-polymer $\mathbf{5 7}$ was readily soluble in DCM, chloroform and THF. The high solubility of ladder-polymers 54 and 57 is indeed intriguing for polymers with such rigid backbones. The iptycene structure has not been introduced into ladder-polymer backbones by other synthetic methods, demonstrating the versatility of the D-A polymerization. However, iptycene units interrupt the conjugation along the backbone, which is reflected in large band gaps of over 3 and $4 \mathrm{eV}$ for ladder-polymers $\mathbf{5 4}$ and 57, respectively.

These examples leave no doubt that the D-A polymerization is one of the most powerful methods for constructing ladder-polymers in a one-pot approach. Especially, the synthesis of fully conjugated ladder-polymers, which can be considered as the narrowest GNRs (vide infra), has thus been addressed since as early as 1970, with more successful examples in the 90s, well before the emergence of the graphene field. Although the reported characterization has remained limited in those days, it could be 
interesting to revisit such ladder-polymers with the present state-of-the-art theoretical and experimental characterization methods.

\section{Synthesis of GNRs through D-A polymerization}

In the last decade, the bottom-up chemical synthesis of GNRs has been intensively investigated and has provided an efficient access to GNRs with atomic precision. This is crucial for the rational control of their electronic, optical and even magnetic properties toward further applications in nanoelectronics, optolectronics and spintronics. $^{26,27}$ The bottom-up fabrication of GNRs could be achieved by both surface-assisted and solution-mediated oxidative cyclization of the PPs with properly designed structures. While the scale of GNRs synthesized by surface-assisted methods is often very limited, the solution-synthesis protocols are more promising to realize the large-scale fabrication and practical applications of GNRs. The solution protocols for GNRs typically start from Suzuki, Yamamoto or Diels-Alder polymerization of tailor-made monomers, giving birth to structurally well-defined PPs that are straightforwardly converted to GNRs by intramolecular oxidative cyclodehydrogenation. ${ }^{26,27}$ Since it was pioneered by Scholl and Clar, the oxidative cyclodehydrogenation, namely Scholl reaction, has been demonstrated to be highly efficient for the synthesis of a wide variety of $\pi$-extended polycyclic aromatic hydrocarbons (PAHs) throughout the 20th century. We further developed this reaction and employed it for planarization of polymeric systems such as PPs, providing GNRs in high quality. Herein, we focus on the recent advances of Diels-Alder polymerization for GNR synthesis.

\section{1 $A_{2} B_{2}$-Type D-A polymerization toward synthesis of GNRs}

The $\mathrm{A}_{2} \mathrm{~B}_{2}$-type $\mathrm{D}$-A polymerization using a bis-Cps and bisacetylene as $\mathrm{A}_{2}$ and $\mathrm{B}_{2}$ monomers toward phenylated PP was illustrated in section II (Table 1). ${ }^{47,49}$ The resulting PPs obtained by this method exhibited high solubility in common organic solvents due to their flexible and twisted geometry, enabling further solution-phase cyclodehydrogenation toward GNRs. In 2000, we undertook our first attempt to planarize soluble PP 7 (Table 1) through intramolecular oxidative cyclodehydrogenation with copper(II) trifluoromethane sulfonate $\left[\mathrm{Cu}\left(\mathrm{CF}_{3} \mathrm{SO}_{3}\right)_{2}\right]$ and aluminum(III) chlorid $\left(\mathrm{AlCl}_{3}\right){ }^{48}$ A partially dehydrogenated polymer $\mathbf{5 9}$ was obtained as demonstrated by IR and Raman spectroscopy (Scheme 12). However, the insolubility of polymer $\mathbf{5 9}$ hindered its further characterization.

Scheme 12. Synthesis of GNRs 59 and $\mathbf{6 2}$ through $\mathrm{A}_{2} \mathrm{~B}_{2}$-type D-A polymerization. 

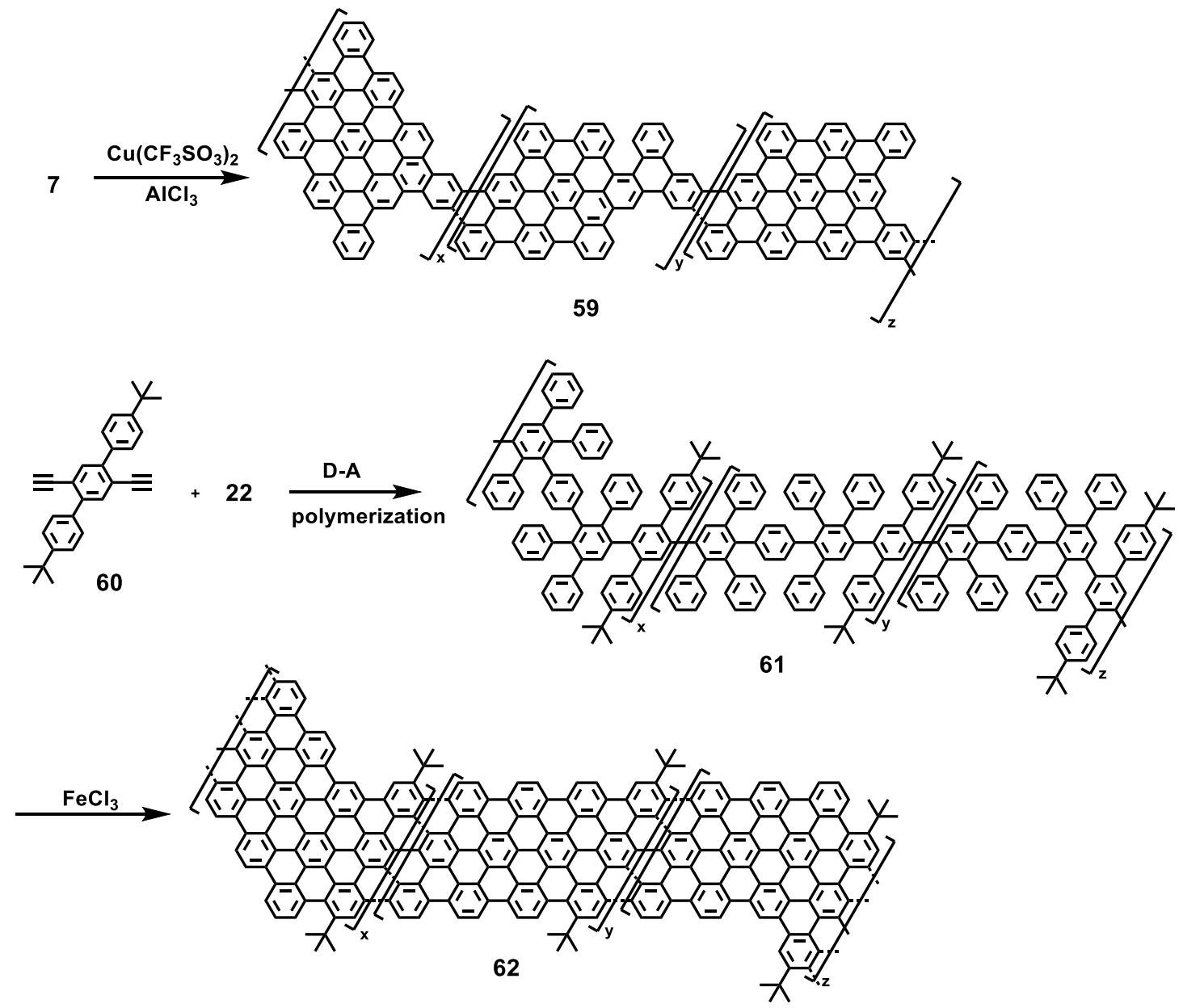

In 2003, we used 1,4-diethynyl-2,5-di(4'-tert-butylphenyl)benzene (60) to react with 4,4'-(1,4-phenylene)bis(2,3,5-triphenylcyclopenta-2,4-dien-1-one) (22) (Scheme 5) for the $\mathrm{A}_{2} \mathrm{~B}_{2}$-type D-A polymerization, producing tert-butyl substituted PP 61 with a DP of 24 (Scheme 11). ${ }^{94}$ The planarization of polymer $\mathbf{6 1}$ was achieved by treatment with iron(III) chloride $\left(\mathrm{FeCl}_{3}\right)$ in nitromethane and DCM, giving GNR 62 . Nevertheless, both GNRs $\mathbf{5 9}$ and $\mathbf{6 2}$ are not linear, but rather contain irregular "kinks" due to the structural isomerization of their PP precursors. In addition, the lengths of these GNRs are limited because of the difficulty in perfectly controlling stoichiometry of the two different monomers used for polymerization, which led to PP precursors with low DP. This is detrimental for the fabrication of single-GNR-based devices.

\subsection{AB-Type D-A polymerization toward synthesis of GNRs}

In comparison with the $\mathrm{A}_{2} \mathrm{~B}_{2}$-type approach, $\mathrm{AB}$-type $\mathrm{D}$-A polymerization can exclude the issue of stoichiometry, leading to PP with high DP and thus produce longer GNRs. In 2014, we reported the first example of "cove"-type GNRs 65a and 65b fabricated by the AB-type D-A polymerization protocol, giving an unprecedented length up to $600 \mathrm{~nm}$ determined from the molecular weight of their alkylated PP 
precursors. $^{95}$ In this work, rationally designed AB-type monomers 63a and 63b, having both a cyclopentadienone as the conjugated diene and an ethynyl group as the dienophile, were used to perform the D-A polymerization and produced alkylated PP precursors 64a and $\mathbf{6 4 b}$, respectively (Scheme 13a). The high efficiency of such an AB-type D-A polymerization was demonstrated by GPC analysis of precursor 64a, giving an unprecedentedly high $M_{n}$ of $340000 \mathrm{~g} \mathrm{~mol}^{-1}$, that corresponded to DP as high as 473 , and a PDI of 1.9. This DP was significantly larger than those of PP precursors produced by the $\mathrm{A}_{2} \mathrm{~B}_{2}$-type $\mathrm{D}$-A polymerization and other metal-catalyzed coupling reactions such as Suzuki and Yamamoto polymerizations. The high molecular weight of 64a was also confirmed by photon-correlation spectroscopy.

Scheme 13. a) Synthesis of GNRs 65 through AB-type D-A polymerization. b) Chlorination of GNR $\mathbf{6 5 c}$ to chlorinated GNR 66.

a
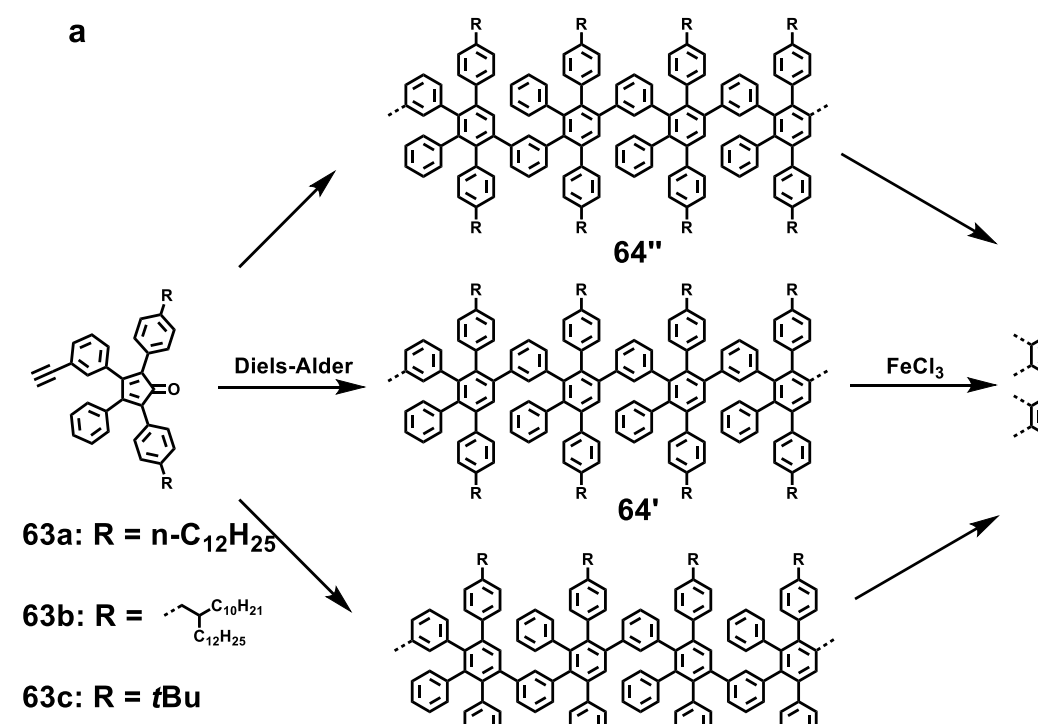

63d: $R=$ COOMe
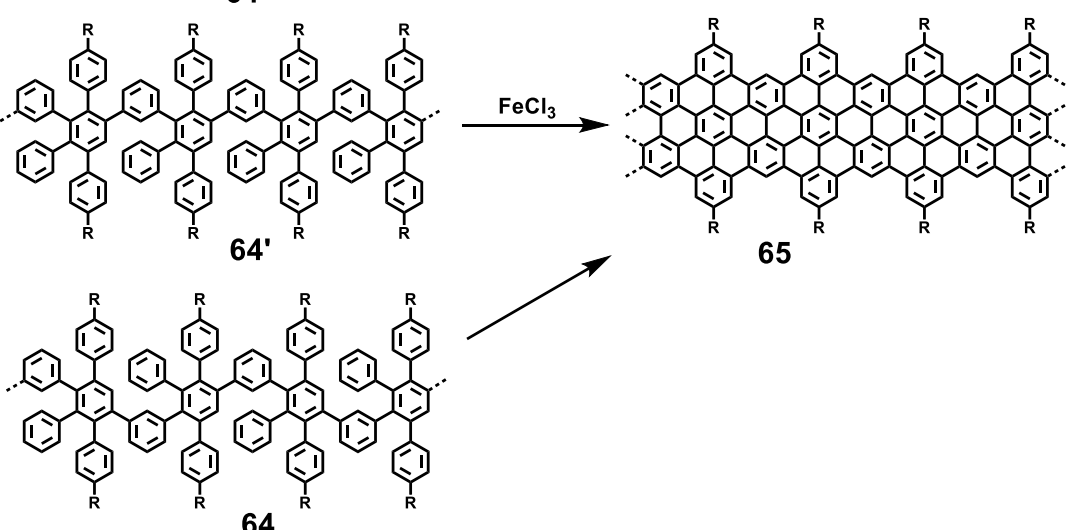

65

b
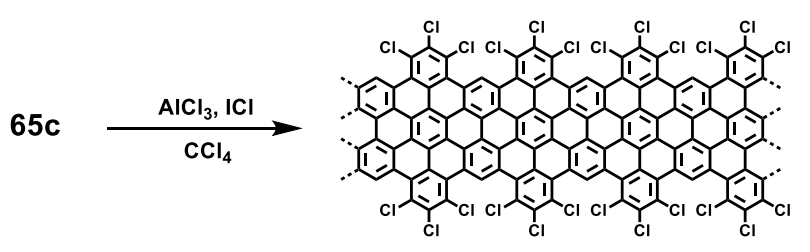

66 

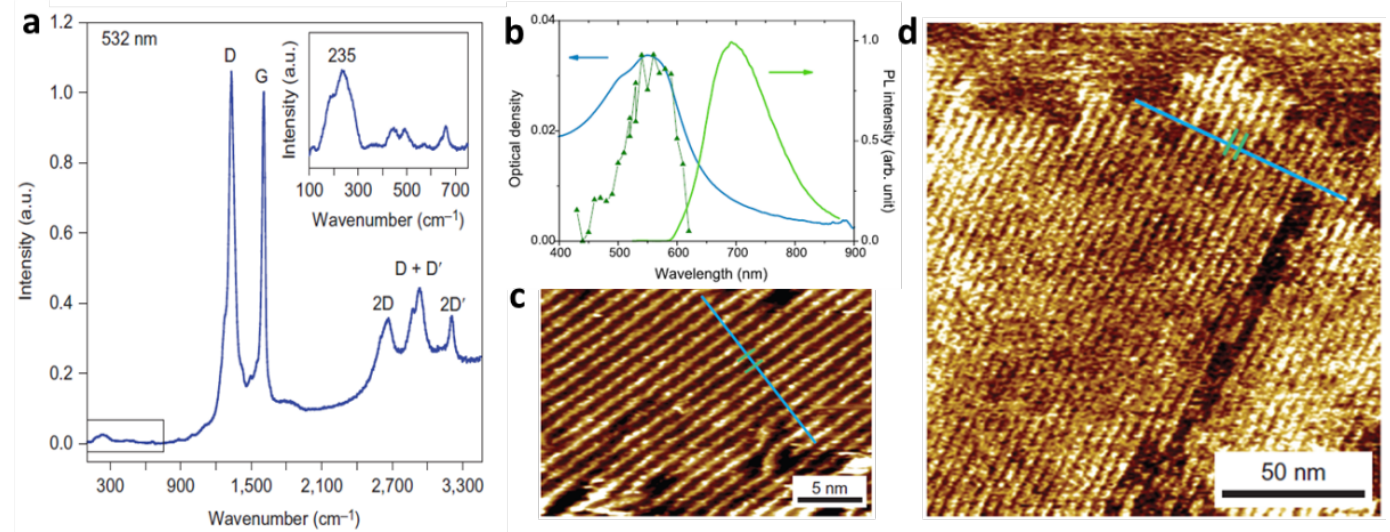

Figure 3. a) Raman spectrum of GNR 65a measured at $532 \mathrm{~nm}(2.33 \mathrm{eV})$ on a powder sample with laser power below $0.1 \mathrm{~mW}$. Inset: a magnified area of the spectrum (black oblong, bottom left) to display a peak from the RBLM at $235 \mathrm{~cm}^{-1}$. Reprint with permission from Ref 95. Copyright 2013 Nature Publishing Group. b) UV-vis absorption, photoluminescence and photoluminescence excitation spectra (triangles) of GNR 65a. Reprint with permission from Ref 96. Copyright 2017 Elsevier Ltd. c) STM image of GNR 65a on HOPG (dry film) demonstrates a well-organized self-assembled monolayer of straight and uniform nanoribbons of up to about $60 \mathrm{~nm}$ in length. Reprint with permission from Ref 95. Copyright 2013 Nature Publishing Group. d) AFM phase image of GNR 65b on HOPG (dry film) demonstrates a highly organized self-assembled monolayer of straight and uniform nanoribbons of over 200 $\mathrm{nm}$ in length. Reprint with permission from Ref 95. Copyright 2013 Nature Publishing Group.

The planarization of polymers 64a and 64b into the corresponding GNRs 65a and $65 \mathbf{b}$, respectively, was performed by intramolecular oxidative cyclodehydrogenation with $\mathrm{FeCl}_{3}$ as the oxidant and Lewis acid. As shown in Scheme 13a, 64a and 64b contained numerous regioisomers because each step of the D-A cycloaddition of monomers as well as intermediate products has two possible orientations. Nonetheless, all of them could lead to the straight and structurally well-defined GNR $\mathbf{6 5 a}$ and $\mathbf{6 5} \mathbf{b}$, respectively, with a theoretically estimated width of $0.69-1.13 \mathrm{~nm}$ (Scheme 13). The high efficiency of cyclodehydrogenation was confirmed by FTIR, Raman, solid-state NMR and UV-vis spectroscopies as well as scanning probe microscopy. The Raman spectrum displayed intense $G$ and $D$ peaks, as well as a distinct peak at $235 \mathrm{~cm}^{-1}$ from the radial breathing-like mode (RBLM), indicating the high uniformity of the width of obtained GNRs (Figure 3a). The photoluminescence spectrum of GNR 65a represented a broad emission peak at $695 \mathrm{~nm}$ with a large Stokes shift of $\sim 135 \mathrm{~nm}$, which might originate from excimer-like states in stacks of individual GNRs or other aggregation-induced effects and is currently under further investigations (Figure 3b). ${ }^{96}$ 
The corresponding photoluminescence excitation was consistent with the absorption band, proving that the observed Stokes shifted luminescence arose from the GNRs. ${ }^{96}$ The scanning tunneling microscopy of GNR 65a and atomic force microscopy (AFM) of GNR $\mathbf{6 5} \mathbf{b}$ revealed the formation of self-assembled monolayers of uniform GNRs on a graphite surface (Figures $3 \mathrm{c}$ and $3 \mathrm{~d}$ ). The optical properties of GNR 65a were further investigated by femtosecond transient absorption spectroscopy, elucidating efficient exciton-exciton annihilation to form a biexcition with a high binding energy of $250 \mathrm{meV}$ as well as stimulated emission from the biexciton state. ${ }^{97}$
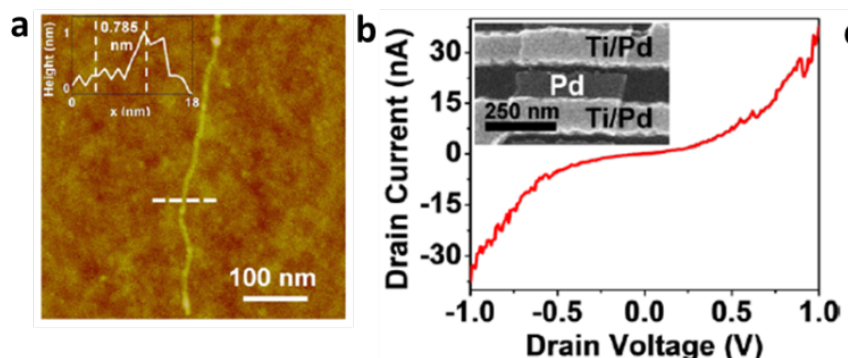

d
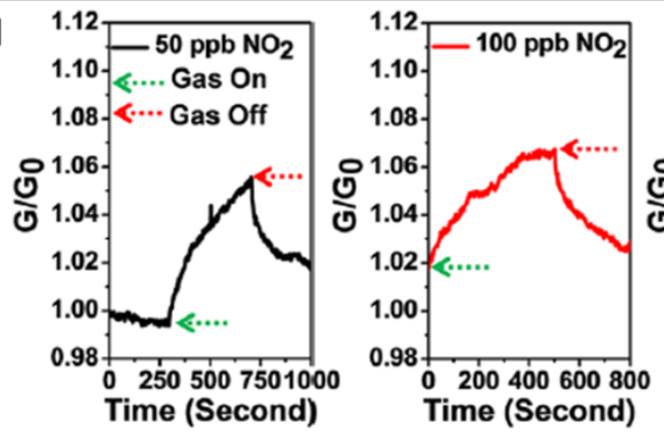
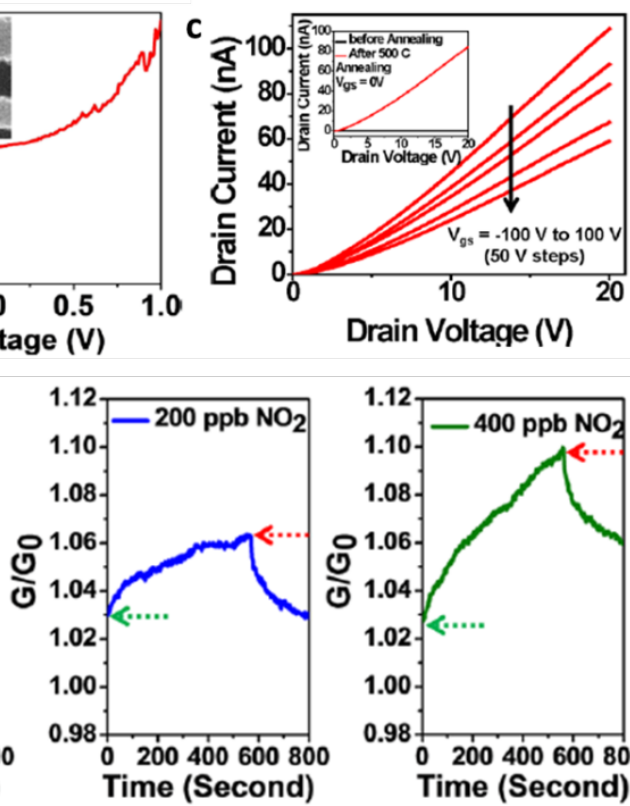

Figure 4. a) AFM tapping-mode height image revealing synthesized GNR 65a length $>500 \mathrm{~nm}$. b) Current $v s$ drain voltage $\left(I-V_{d}\right)$ characteristic of an individual GNR 65a device. Inset shows a scanning electron microscopy image of a $20 \mathrm{~nm}$ gap between $\mathrm{Ti} / \mathrm{Pd}$ and angle-deposited Pd. c) Current $v s$ drain voltage $\left(I-V_{d}\right)$ of a typical GNR 65a film device under different gate voltages $\left(V_{g s}\right)$. d) Time domain normalized conductance $\left(G / G_{0}\right)$ of the GNR 65a film device during introduction of different concentrations of $\mathrm{NO}_{2}$. Green arrows correspond to the device being exposed to a certain concentration of $\mathrm{NO}_{2}$, while red arrows correspond to the device being flushed with Ar only. Reprint with permission from Ref 98. Copyright 2014 American Chemical Society.

For the fabrication of single-GNR-based devices, it is essential to deposit isolated GNRs, which was achieved by immersing alkyl-functionalized $\mathrm{Si} / \mathrm{SiO}_{2}$ substrates in a dispersion of GNR 65a, revealing a length over $500 \mathrm{~nm}$ visualized by AFM (Figure 4a). ${ }^{98,99}$ The length distribution of GNR 65a observed by AFM was in good 
agreement with the molecular weight distribution of the corresponding alkylated PP precursor 64a based on their GPC analysis. ${ }^{98}$ Such individual GNR strands could then be used to fabricate single molecule devices, exhibiting electrical conduction (Figure 4b). ${ }^{99}$ Moreover, thin film devices based on GNR 65a were also fabricated by drop casting the GNR dispersion on the functionalized $\mathrm{Si} / \mathrm{SiO}_{2}$ substrates. The conductivity could be significantly enhanced after annealing at $500{ }^{\circ} \mathrm{C}$ in $\mathrm{H}_{2} / \mathrm{Ar}$ gases, which removed the insulating alkyl chains from the GNR edges (Figure 4c). The applicability of such GNR films as $\mathrm{NO}_{2}$ gas sensor has been demonstrated, with limits of detection down to $50 \mathrm{ppb}$ (Figure 4d). GNR 65a dispersed in a water/surfactant mixture was also employed to fabricate field-effect transistors (FETs) based on isolated GNR strands, demonstrating high conductivity with a large drain current of $70 \mu \mathrm{A} .{ }^{100}$ Nevertheless, the on-off ratio was still very small, presumably due to unintentional stacking of GNRs, which was theoretically shown to reduce the band gap. The on-off ratio could recently be improved by employing electrospray ionization deposition as well as graphene-based electrodes instead of metal electrodes to establish a better contact with the GNRs. ${ }^{101}$ In addition, on-surface synthesized GNRs have been investigated as semiconductor materials in FET devices, displaying higher on-off ratios than those of FETs based on solution synthesized GNRs. For example, recently Bokor and coworkers demonstrated high-performance FETs with on-surface derived GNRs, presenting a high on-current of $\sim 1 \mu \mathrm{A}$ and an on-off ratio of $\sim 10^{5} .{ }^{102}$ More recently, we reported a structurally defined GNR constructed by ambient-pressure chemical vapor deposition. The resulting FET device based on this GNR also exhibited a high on-off ratio. ${ }^{103}$ However, further efforts and improvements in the deposition and device fabrication are required for achieving better performing devices as well as for studying the intrinsic electronic properties of the GNRs in the device configurations.

a

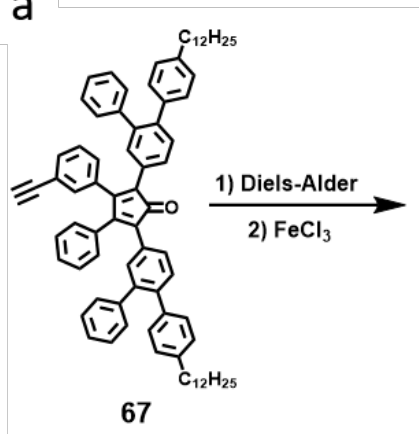

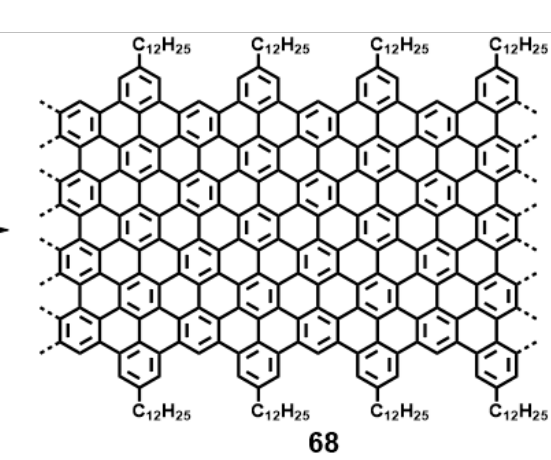

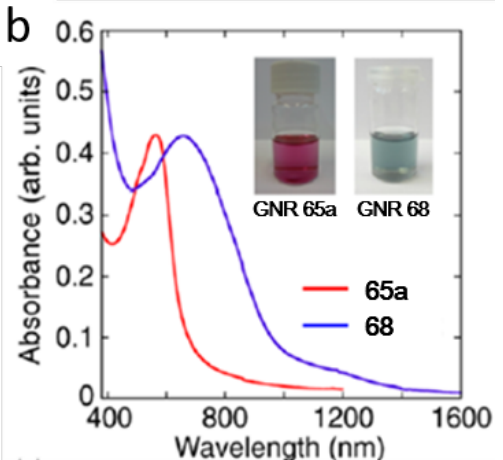

Figure 5. a) Synthesis of GNRs 68 through AB-type D-A polymerization of monomer 67. b) UV-vis-NIR absorption spectra of GNRs $\mathbf{6 5 a}$ and 68 in THF. Inset: 
Photographs of dispersions of GNRs 65a and 68 in THF. Reprint with permission from Ref 104. Copyright 2014, American Chemical Society.

Scheme 14. Structures of edge- and cove-substituted GNRs 69 and 70.

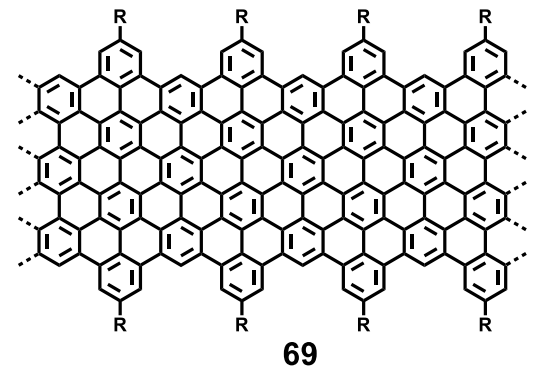

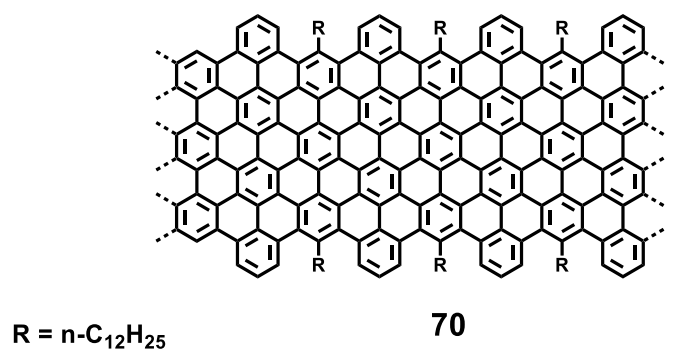

70

On the other hand, the functionalization of the edges of GNR 65 has been investigated to tune the electronic and optical properties as well as to bestow other functions on the GNRs. We have demonstrated the edge chlorination of tert-butyl substituted GNR $\mathbf{6 5 c}$, leading to chlorinated GNR 66 with lowered energy levels and red-shifted absorption (Scheme 13b). ${ }^{105}$ More recently, Fischer and coworkers synthesized GNR 65d bearing methyl esters and prepared composites with gold nanoparticles, which showed enhanced catalytic performance for the electrocatalytic reduction of $\mathrm{CO}_{2}{ }^{106}$ This was probably because the GNR matrix effectively prevented the assembly of gold nanoparticles into larger aggregates.

For further modulating the optoelectronic properties of the GNRs, it is essential to change their widths and edge structures. We have achieved the lateral extension of GNR 65 by using lateral extended monomer 67 with four extra benzene rings instead of monomer $63,{ }^{104}$ following the same sequence of the AB-type D-A polymerization and intramolecular cyclodehydrogenation (Figure 5a). ${ }^{3}$ The resulting GNR 68 exhibited a broader absorption pattern and a lowered optical band gap of $\sim 1.2 \mathrm{eV}$ compared to $\sim 1.9 \mathrm{eV}$ of the narrower GNR 65, demonstrating a width-dependent band gap modulation (Figure 5b). We have more recently synthesized two GNRs (69 and 70) with the same edge structure of GNR $\mathbf{6 5}$ and intermediate width between $\mathbf{6 5}$ and 68 (Scheme 14). GNR 69 with dodecyl chains attached to the outermost positions has a planar conjugated structure, whereas $\mathbf{7 0}$ with the dodecyl chains at the innermost positions possesses a distorted geometry based on theoretical studies. The structural distortion lowered the band gap of GNR 70 compared to GNR 69, accomplishing further band gap tuning. Raman spectra of GNRs 65, 68 and 69 displayed shifts of the low-energy radial-breathing-like mode (RBLM) peak from 130 to $230 \mathrm{~cm}^{-1}$ as predicted by theoretical calculations. ${ }^{107}$ Moreover, the photoconductivities of GNRs 60, 69 and 70 were compared using time-resolved terahertz spectroscopy, which suggested that the structural distortion by alkyl chain substitution has little effect on 
the photoconductive properties, while the width and edge structures of GNRs play a more significant role. ${ }^{108}$

Recently, Gorodetsky and coworkers proposed a novel AB-type aza-D-A (Povarov) polymerization method towards the synthesis of a nitrogen-doped $N=7$ armchair GNR 72 (Scheme 15). ${ }^{109}$ Monomer precursor 71, which was furnished with a $\mathrm{N}$-naphthalenylmethanimine as the diene and an ethynyl group as the dienophile, was employed for aza-D-A polymerization to give polybenzoquinoline $\mathbf{7 2}$. Polymer 72 featured a DP of up to 43 and a PDI of 1.4, based on the GPC analysis. Polybenzoquinoline $\mathbf{7 2}$ could potentially be used as precursor for GNR 73, although the further planarization of $\mathbf{7 2}$ was not described.

Scheme 15. Proposed synthesis of nitrogen-doped GNR 73 through AB-type aza-D-A polymerization.

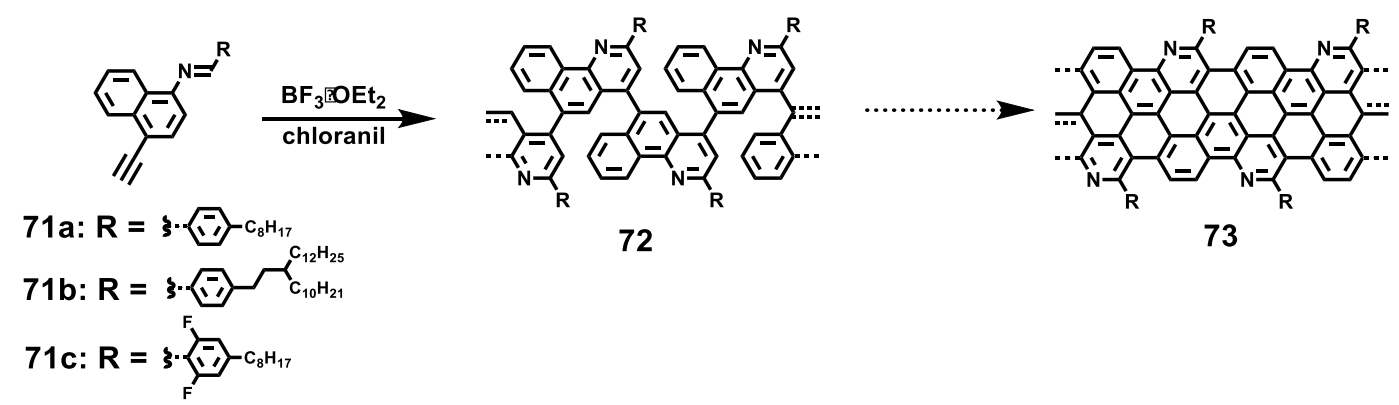

In addition to the present D-A polymerization protocols, metal-catalyzed polymerization approaches have also been utilized toward the construction of GNRs, including the $\mathrm{A}_{2} \mathrm{~B}_{2}$-type ${ }^{110-113}$ and $\mathrm{AB}$-type ${ }^{114,115}$ Suzuki polymerization, as well as AA-type Yamamoto polymerization ${ }^{116-118}$. Recently, Rubin and coworkers developed a new synthetic approach to GNRs through topochemical polymerization of butadiyne -containing monomers followed by aromatization at high temperature. ${ }^{119}$ However, all these synthesis concepts except the AB-type D-A polymerization could only provide GNRs with lengths limited to dozens of nanometers, which still needed further efforts.

\section{Conclusion and outlook.}

The classical Diels-Alder reaction is still catching contemporary molecular architects' eyes in the field of synthetic polymer chemistry with increasing importance. The appearance of the $\mathrm{A}_{2} \mathrm{~B}_{2}$-type $\mathrm{D}$-A polymerization using cyclopentadienones gave birth to a class of functional phenylated PP materials. With their high DP, these PPs exhibited promising applications as polymer membranes, especially as PEMs. Such polymer membranes displayed comparable and sometimes even superior performance than the cutting edge materials applied in the field of gas separation, anionic/cationic 
fuel cells, battery and electrodialysis. However, more efforts should still be made to reduce water uptake and increase proton conductivity and device durability of the PEMs of PPs as well as to achieve a better understanding of their structure-property relationship. D-A reactions could also be used to synthesize hyperbranched PPs. In contrast to molecularly defined PP dendrimers synthesized step-by-step, hyperbranched PPs could provide 3D macromolecular architectures with higher simplicity and efficiency, through uncontrolled one-pot D-A polymerization, albeit compromised structural precision. The degree of branching of these hyperbranched PPs could be controlled by adjusting the stoichiometry of the different monomeric building blocks. To incorporate these hyperbranched PPs as well as phenylated PPs synthesized via other protocols, such as AB-type D-A polymerization, into development of functional PPs with new archetechtures would reinforce the PP-based polymer membrane applications thriving in the past decade.

The D-A reaction has played a crucial role in the history of ladder-polymer synthesis. D-A polymerization, especially those using 1,2,5,6-tetramethylenecyclooctane and 1,2,4,5-tetramethylenecyclohexane, cyclopentadienone, benzo-[1,2-c:4,5-c']difuran and anthracene as dienes, have allowed the synthesis of ladder-polymers involving unique structural features such as rigid iptycene and semi-flexible cyclooctadiene. The semi-flexible ladder-polymers containing cyclooctadiene confined the complicated three-dimensional motion of the polymer chains to two dimension. Such a design would be interesting for fundamental studies of polymer folding and self-assembly. Moreover, fully conjugated ladder-type poly(fluranthene) with similar structure as the belt region of $\mathrm{C}_{60}$ were also achieved by D-A polymerization, showing extension of optical absorption over $600 \mathrm{~nm}$, which suggested a long effective conjugation length. These examples demonstrated that D-A reaction is undoubtedly one of the most powerful reactions for constructing ladder-polymers in a one-pot polymerization. However, the requirement for the one-pot polymerization renders the monomer structures relatively more complicated and difficult to access, which seems to be the reason for the limited number of new examples in the last decade. With the emerging field of GNRs, ladder-polymers, in particular fully conjugated ladder-polymers as the narrowest GNRs, could attract renewed attention in chemistry as well as in physics.

Finally, D-A polymerization offers a promising approach towards high DP polyphenylene precursors for bottom-up GNR synthesis. In particular, the AB-type D-A polymerization furnished the GNRs with an unprecedented length of over 600 $\mathrm{nm}$, which surpassed GNRs constructed by other reactions including metal-catalysed aryl-aryl coupling, which typically possess lengths up to around $100 \mathrm{~nm}$. Furthermore, the width of the GNRs can be modulated by expanding the monomer structure, 
allowing for the tuning of their optoelectronic properties. Nevertheless, the successful GNR synthesis through the AB-type D-A reaction is thus far only limited to monomers based on ethynyl-substituted Cps. Therefore, the next challenge should be the design of new AB-type monomers equipped with different dienes and dienophiles for synthesizing a further variety of GNRs with unique structures, heteroatom-doping, and/or added functional groups, while preserving the length exceeding $100 \mathrm{~nm}$. It is especially desirable to synthesize low-band gap GNRs with infrared absorption without broadening the ribbons and thus keeping the high processability, which might be possible by incorporating zigzag and/or cove edges or heteroatom-dopants. Such synthetic advancements would be a key to enriching the GNR family and paving the way towards their future applications in nanoelectronics and optoelectronics.

\section{Acknowledgements}

We acknowledge our distinguished partner groups and dedicated associates, who enabled our contributions to the achievements described in this article. We thank for the financial support by EC through MoQuaS (Molecular Quantum Spintronics FP7-ICT-2013-10 610449), Marie-Curie ITN project “iSwitch" (GA No. 642196), and Graphene Flagship, ERC-Adv.-Grant 267160 (NANOGRAPH), the Max Planck Society, the Office of Naval Research BRC Program (molecular synthesis and characterization) and DFG Priority Program SPP 1459. We are also thankful to fruitful collaborations with BASF SE, Ludwigshafen.

\section{References}

1. Diels, O. \& Alder, K. Synthesen in der hydroaromatischen Reihe. Justus Liebig's Annalen der Chemie 460, 98-122 (1928).

2. Nicolaou, K.C., Snyder, S.A., Montagnon, T. \& Vassilikogiannakis, G. The Diels-Alder Reaction in Total Synthesis. Angewandte Chemie International Edition 41, 1668-1698 (2002).

3. Ramdas, M.R., Kumar, K.S.S. \& Nair, C.P.R. Click polymerizations: Encouraging route for shape memory polymers. Materials Letters 172, 216-221 (2016).

4. Knall, A.C. \& Slugovc, C. Inverse electron demand Diels-Alder (iEDDA)-initiated conjugation: a (high) potential click chemistry scheme.

Chem Soc Rev 42, 5131-5142 (2013).

5. Nandivada, H., Jiang, X. \& Lahann, J. Click Chemistry: Versatility and Control in the Hands of Materials Scientists. Advanced Materials 19, 2197-2208 (2007). 
6. Tasdelen, M.A. Diels-Alder "click" reactions: recent applications in polymer and material science. Polymer Chemistry 2, 2133 (2011).

7. Hizal, G., Tunca, U. \& Sanyal, A. Discrete macromolecular constructs via the Diels-Alder "Click" reaction. Journal of Polymer Science Part A: Polymer Chemistry 49, 4103-4120 (2011).

8. Kovacic, P. \& Kyriakis, A. Polymerization of Benzene top-Polyphenyl by Aluminum Chloride-Cupric Chloride. Journal of the American Chemical Society 85, 454-458 (1963).

9. Berresheim, A.J., Müller, M. \& Müllen, K. Polyphenylene Nanostructures. Chem Rev 99, 1747-1786 (1999).

10. Watson, M.D., Fechtenkötter, A. \& Müllen, K. Big Is Beautiful-“Aromaticity” Revisited from the Viewpoint of Macromolecular and Supramolecular Benzene Chemistry. Chemical Reviews 101, 1267-1300 (2001).

11. Hammer, B.A.G. \& Müllen, K. Dimensional Evolution of Polyphenylenes: Expanding in All Directions. Chem Rev 116, 2103-2140 (2016).

12. Bieri, M., Treier, M., Cai, J., Aït-Mansour, K., Ruffieux, P., Gröning, O., Gröning, P., Kastler, M., Rieger, R., Feng, X., Müllen, K. \& Fasel, R. Porous graphenes: two-dimensional polymer synthesis with atomic precision. Chem Commun (Camb), 6919-6921 (2009).

13. Newby, J.J., Liu, C.-P., Müller, C.W., James, W.H., Buchanan, E.G., Lee, H.D. \& Zwier, T.S. Spectroscopy and Photophysics of Structural Isomers of Naphthalene:Z-Phenylvinylacetylene†. The Journal of Physical Chemistry A 114, 3190-3198 (2010).

14. Türp, D., Nguyen, T.-T.-T., Baumgarten, M. \& Müllen, K. Uniquely versatile: nano-site defined materials based on polyphenylene dendrimers. New J Chem 36, 282-298 (2012).

15. Hammer, B.A., Moritz, R., Stangenberg, R., Baumgarten, M. \& Müllen, K. The polar side of polyphenylene dendrimers. Chem Soc Rev 44, 4072-4090 (2015).

16. Scherf, U. \& Müllen, K. Polyarylenes and poly(arylenevinylenes), 7. A soluble ladder polymer via bridging of functionalized poly(p-phenylene)-precursors. Die Makromolekulare Chemie, Rapid Communications 12, 489-497 (1991).

17. Jones, R.G., Wilks, E.S., Metanomski, W.V., Kahovec, J., Hess, M., Stepto, R. \& Kitayama, T. Compedium of polymer terminology and nomenclature IUPAC recommendations (The Royal Society of Chemistry, Cambridge, 2009). 
18. Lee, J., Kalin, A.J., Yuan, T., Al-Hashimi, M. \& Fang, L. Fully conjugated ladder polymers. Chem Sci 8, 2503-2521 (2017).

19. Grozema, F.C., van Duijnen, P.T., Berlin, Y.A., Ratner, M.A. \& Siebbeles, L.D.A. Intramolecular Charge Transport along Isolated Chains of Conjugated Polymers: Effect of Torsional Disorder and Polymerization Defects. The Journal of Physical Chemistry B 106, 7791-7795 (2002).

20. Prins, P., Grozema, F.C., Schins, J.M., Patil, S., Scherf, U. \& Siebbeles, L.D.A. High Intrachain Hole Mobility on Molecular Wires of Ladder-Type Poly(p-Phenylenes). Physical Review Letters 96, 146601 (2006).

21. Samiullah, M., Moghe, D., Scherf, U. \& Guha, S. Diffusion length of triplet excitons in organic semiconductors. Physical Review B 82, 205211 (2010).

22. Grimsdale, A.C. \& Müllen, K. Polyphenylene-type Emissive Materials: Poly(para-phenylene)s, Polyfluorenes, and Ladder Polymers. 199, 1-82 (2006).

23. Bheemireddy, S.R., Hautzinger, M.P., Li, T., Lee, B. \& Plunkett, K.N. Conjugated Ladder Polymers by a Cyclopentannulation Polymerization. J Am Chem Soc 139, 5801-5807 (2017).

24. Scherf, U. Ladder-type materials. Journal of Materials Chemistry $\mathbf{9}$, 1853-1864 (1999).

25. Schlüter, A.-D. Ladder Polymers: The new generation. Advanced Materials 3, 282-291 (1991).

26. Narita, A., Wang, X.Y., Feng, X. \& Müllen, K. New advances in nanographene chemistry. Chem Soc Rev 44, 6616-6643 (2015).

27. Narita, A., Feng, X. \& Müllen, K. Bottom-up synthesis of chemically precise graphene nanoribbons. Chem Rec 15, 295-309 (2015).

28. Chen, L., Hernandez, Y., Feng, X. \& Müllen, K. From nanographene and graphene nanoribbons to graphene sheets: chemical synthesis. Angew Chem Int Edit 51, 7640-7654 (2012).

29. Schwierz, F. Graphene transistors. Nature Nanotechnology 5, 487-496 (2010).

30. Ritter, K.A. \& Lyding, J.W. The influence of edge structure on the electronic properties of graphene quantum dots and nanoribbons. Nat Mater 8, 235-242 (2009).

31. Yazyev, O.V. A guide to the design of electronic properties of graphene nanoribbons. Accounts Chem Res 46, 2319-2328 (2013).

32. Li, X., Wang, X., Zhang, L., Lee, S. \& Dai, H. Chemically derived, ultrasmooth graphene nanoribbon semiconductors. Science 319, 1229-1232 (2008). 
33. Wang, X.R., Shi, Y. \& Zhang, R. Field-effect transistors based on two-dimensional materials for logic applications. Chinese Phys B 22, 098505 (2013).

34. Marmolejo-Tejada, J.M. \& Velasco-Medina, J. Review on graphene nanoribbon devices for logic applications. Microelectron J 48, 18-38 (2016).

35. Osella, S., Narita, A., Schwab, M.G., Hernandez, Y., Feng, X., Müllen, K. \& Beljonne, D. Graphene nanoribbons as low band gap donor materials for organic photovoltaics: quantum chemical aided design. Acs Nano 6, 5539-5548 (2012).

36. Villegas, C.E., Mendonca, P.B. \& Rocha, A.R. Optical spectrum of bottom-up graphene nanoribbons: towards efficient atom-thick excitonic solar cells. Sci Rep-Uk 4, 6579 (2014).

37. Han, M.Y., Özyilmaz, B., Zhang, Y. \& Kim, P. Energy band-gap engineering of graphene nanoribbons. Phys Rev Lett 98, 206805 (2007).

38. Chen, Z.H., Lin, Y.M., Rooks, M.J. \& Avouris, P. Graphene nano-ribbon electronics. Physica E 40, 228-232 (2007).

39. Tapasztó, L., Dobrik, G., Lambin, P. \& Biró, L.P. Tailoring the atomic structure of graphene nanoribbons by scanning tunnelling microscope lithography. Nat Nanotechnol 3, 397-401 (2008).

40. Kosynkin, D.V., Higginbotham, A.L., Sinitskii, A., Lomeda, J.R., Dimiev, A., Price, B.K. \& Tour, J.M. Longitudinal unzipping of carbon nanotubes to form graphene nanoribbons. Nature 458, 872-U875 (2009).

41. Jiao, L., Zhang, L., Wang, X., Diankov, G. \& Dai, H. Narrow graphene nanoribbons from carbon nanotubes. Nature 458, 877-880 (2009).

42. Gandini, A. The furan/maleimide Diels-Alder reaction: A versatile clickunclick tool in macromolecular synthesis. Progress in Polymer Science 38, 1-29 (2013).

43. Cava, M.P. \& Deana, A.A. Condensed Cyclobutane Aromatic Compounds. VI. The Pyrolysis of 1,3-Dihydroisothianaphthene-2,2-dioxide: A New Synthesis of Benzocyclobutene1. Journal of the American Chemical Society 81, 4266-4268 (1959).

44. Goodall, G.W. \& Hayes, W. Advances in cycloaddition polymerizations. Chem Soc Rev 35, 280-312 (2006).

45. Ried, W. \& Bönnighausen, K.H. Diensynthesen mit Diinen. Chemische Berichte 93, 1769-1773 (1960).

46. Fieser, L.F. Hexaphenylbenzene. Organic Syntheses 46, 44 (1966). 
47. Stille, J.K., Harris, F.W., Rakutis, R.O. \& Mukamal, H. Diels-Alder polymerizations: Polymers containing controlled aromatic segments. Journal of Polymer Science Part B: Polymer Letters 4, $791-793$ (1966).

48. Ried, W. \& Freitag, D. Synthese von Polyphenyl-poly-phenylen. Die Naturwissenschaften 53, 306-306 (1966).

49. Mukamal, H., Harris, F.W. \& Stille, J.K. Diels-Alder polymers. III. Polymers containing phenylated phenylene units. Journal of Polymer Science Part A-1: Polymer Chemistry 5, 2721-2729 (1967).

50. Stille, J.K., Rakutis, R.O., Mukamal, H. \& Harris, F.W. Diels-Alder Polymerizations. IV. Polymers Containing Short Phenylene Blocks Connected by Alkylene Units. Macromolecules 1, 431-436 (1968).

51. Stille, J.K. \& Noren, G.K. Diels-alder polymers: Polyphenylenes containing alternating phenylene and triphenylphenylene units (1). Journal of Polymer Science Part B: Polymer Letters 7, 525-527 (1969).

52. Wrasidlo, W. \& Augl, J.M. Preparation of poly(octaphenyl-tetraphenylene). Journal of Polymer Science Part B: Polymer Letters 7, 519-523 (1969).

53. Speight, J.G., Kovacic, P. \& Koch, F.W. Synthesis and Properties of Polyphenyls and Polyphenylenes. Journal of Macromolecular Science, Part C: Polymer Reviews 5, 295-386 (1971).

54. Noren, G.K. \& Stille, J.K. Polyphenylenes. Journal of Polymer Science: Macromolecular Reviews 5, 385-430 (1971).

55. Kumar, U. \& Neenan, T.X. Diels-Alder Polymerization between Bis(cyclopentadienones) and Acetylenes. A Versatile Route to New Highly Aromatic Polymers. Macromolecules 28, 124-130 (1995).

56. Shifrina, Z.B., Averina, M.S., Rusanov, A.L., Wagner, M. \& Müllen, K. Branched polyphenylenes by repetitive Diels-Alder cycloaddition. Macromolecules 33, 3525-3529 (2000).

57. Suh, D., Jung, S.-H., Park, S.-J., Kim, D. \& Cho, H.-N. Synthesis and Properties of Highly Phenyl-Substituted Fluorene Copolymers Containing Hole and Electron Transporting Moieties Via Diels-Alder Polymerization. Molecular Crystals and Liquid Crystals 424, 159-165 (2004).

58. Largier, T., Huang, F. \& Cornelius, C.J. Homopolymer and multi-block Diels-Alder polyphenylenes: Synthesis, physical properties, X-ray diffraction, and gas transport. European Polymer Journal 89, 301-310 (2017).

59. Lim, Y., Lee, H., Lee, S., Jang, H., Hossain, M.A., Cho, Y., Kim, T., Hong, Y. \& Kim, W. Synthesis and properties of sulfonated poly(phenylene sulfone)s without ether linkage by Diels-Alder reaction for PEMFC application. Electrochim Acta 119, 16-23 (2014). 
60. Kerry, F.G. Industrial Gas Handbook: Gas Separation and Purification, (Taylor and Francis Group, LLC, Boca Raton, 2006).

61. Bernardo, P., Drioli, E. \& Golemme, G. Membrane Gas Separation: A Review/State of the Art. Industrial \& Engineering Chemistry Research 48 , 4638-4663 (2009).

62. Wang, Y., Chen, K.S., Mishler, J., Cho, S.C. \& Adroher, X.C. A review of polymer electrolyte membrane fuel cells: Technology, applications, and needs on fundamental research. Applied Energy 88, 981-1007 (2011).

63. Kreuer, K.D. Ion Conducting Membranes for Fuel Cells and other Electrochemical Devices. Chem Mater 26, 361-380 (2014).

64. Hickner, M.A., Ghassemi, H., Kim, Y.S., Einsla, B.R. \& McGrath, J.E. Alternative Polymer Systems for Proton Exchange Membranes (PEMs). Chemical Reviews 104, 4587-4612 (2004).

65. Fujimoto, C.H., Hickner, M.A., Cornelius, C.J. \& Loy, D.A. Ionomeric Poly(phenylene) Prepared by Diels-Alder Polymerization: Synthesis and Physical Properties of a Novel Polyelectrolyte. Macromolecules 38, 5010-5016 (2005).

66. Hickner, M.A., Fujimoto, C.H. \& Cornelius, C.J. Transport in sulfonated poly(phenylene)s: Proton conductivity, permeability, and the state of water. Polymer 47, 4238-4244 (2006).

67. Hibbs, M.R., Fujimoto, C.H. \& Cornelius, C.J. Synthesis and Characterization of Poly(phenylene)-Based Anion Exchange Membranes for Alkaline Fuel Cells. Macromolecules 42, 8316-8321 (2009).

68. Stanis, R.J., Yaklin, M.A., Cornelius, C.J., Takatera, T., Umemoto, A., Ambrosini, A. \& Fujimoto, C.H. Evaluation of hydrogen and methanol fuel cell performance of sulfonated diels alder poly(phenylene) membranes. Journal of Power Sources 195, 104-110 (2010).

69. Largier, T.D., Wang, D., Mueller, J. \& Cornelius, C.J. Improving electrodialysis based water desalination using a sulfonated Diels-Alder poly(phenylene). Journal of Membrane Science 531, 103-110 (2017).

70. Fujimoto, C., Kim, S., Stains, R., Wei, X.L., Li, L.Y. \& Yang, Z.G. Vanadium redox flow battery efficiency and durability studies of sulfonated Diels Alder poly(phenylene)s. Electrochem Commun 20, 48-51 (2012).

71. Skalski, T.J., Britton, B., Peckham, T.J. \& Holdcroft, S. Structurally-defined, sulfo-phenylated, oligophenylenes and polyphenylenes. J Am Chem Soc 137, 12223-12226 (2015). 
72. Adamski, M., Skalski, T.J.G., Britton, B., Peckham, T.J., Metzler, L. \& Holdcroft, S. Highly Stable, Low Gas Crossover, Proton-Conducting Phenylated Polyphenylenes. Angew Chem Int Edit 56, 9058-9061 (2017).

73. Voit, B.I. \& Lederer, A. Hyperbranched and highly branched polymer architectures--synthetic strategies and major characterization aspects. Chem Rev 109, 5924-5973 (2009).

74. Morgenroth, F. \& Müllen, K. Dendritic and hyperbranched polyphenylenes via a simple Diels-Alder route. Tetrahedron 53, 15349-15366 (1997).

75. Zhi, L., Wu, J., Li, J., Stepputat, M., Kolb, U. \& Müllen, K. Diels-Alder Reactions of Tetraphenylcyclopentadienones in Nanochannels: Fabrication of Nanotubes from Hyperbranched Polyphenylenes. Advanced Materials 17, 1492-1496 (2005).

76. Stumpe, K., Komber, H. \& Voit, B.I. Novel Branched Polyphenylenes based on $\mathrm{A} 2 / \mathrm{B} 3$ and $\mathrm{AB} 2 / \mathrm{AB}$ Monomers via Diels-Alder Cycloaddition. Macromolecular Chemistry and Physics 207, 1825-1833 (2006).

77. Kuchkina, N.V., Zinatullina, M.S., Serkova, E.S., Vlasov, P.S., Peregudov, A.S. \& Shifrina, Z.B. Hyperbranched pyridylphenylene polymers based on the first-generation dendrimer as a multifunctional monomer. Rsc Adv 5, 99510-99516 (2015).

78. Bailey, W.J., Economy, J. \& Hermes, M.E. Polymers. IV. Polymeric Diels-Alder Reactions. The Journal of Organic Chemistry 27, 3295-3299 (1962).

79. Kohnke, F.H., Slawin, A.M.Z., Stoddart, J.F. \& Williams, D.J. Molecular Belts and Collars in the Making: A Hexaepoxyoctacosahydro[12]cyclacene Derivative. Angewandte Chemie International Edition in English 26, 892-894 (1987).

80. Wegener, S. \& Müllen, K. New ladder polymers via repetitive Diels-Alder reaction under high pressure. Macromolecules 26, 3037-3040 (1993).

81. Wegener, S. \& Müllen, K. 5,6,7,8-Tetramethylenebicyclo[2.2.2]oct-2-ene as "Bis(diene)" in Repetitive Diels-Alder Reactions. Chemische Berichte 124, 2101-2103 (1991).

82. Pollmann, M., Wohlfarth, W., Müllen, K. \& Lex, J. 1,2,5,6-Tetra-exo-methylenecynclooctane and [2.2]-(2,3)- Furanophane as bis-diene components in diels-alder reactions. Tetrahedron Letters $\mathbf{3 1}$, 2701-2704 (1990).

83. Pollmann, M. \& Müllen, K. Semiflexible Ribbon-type Structures via Repetitive Diels-Alder Cycloaddition. Cage Formation versus Polymerization. Journal of the American Chemical Society 116, 2318-2323 (1994). 
84. Stille, J.K., Noren, G.K. \& Green, L. Hydrocarbon ladder aromatics from a Diels-Alder reaction. Journal of Polymer Science Part A-1: Polymer Chemistry 8, 2245-2254 (1970).

85. Schlüter, A.D., Löffler, M. \& Enkelmann, V. Synthesis of a Fully Unsaturated All-Carbon Ladder Polymer. Nature 368, 831-834 (1994).

86. Blatter, K. \& Schlüter, A.D. Ribbon-Shaped Structures Via Repetitive Diels-Alder Reaction - a Polycatafusene. Macromolecules 22, 3506-3508 (1989).

87. Vogel, T., Blatter, K. \& Schlüter, A.D. A Soluble Polyacene Precursor. Makromol Chem-Rapid 10, 427-430 (1989).

88. Löffler, M., Schlüter, A.D., Gessler, K., Saenger, W., Toussaint, J.M. \& Brédas, J.L. Synthesis of a Fully Unsaturated Molecular Board. Angewandte Chemie-International Edition in English 33, 2209-2212 (1994).

89. Luo, J. \& Hart, H. Bisannelation with a benzo[1,2-c:4,5-c']difuran equivalent: a new route to linear acene derivatives. The Journal of Organic Chemistry 53, 1341-1343 (1988).

90. Zhao, D. \& Swager, T.M. Conjugated polymers containing large soluble diethynyl iptycenes. Org Lett 7, 4357-4360 (2005).

91. Hopf, H. Classics in Hydrocarbon Chemistry: Syntheses, Concepts, Perspectives (Wiley-VCH, Weinheim, 2000).

92. Thomas, S.W., 3rd, Long, T.M., Pate, B.D., Kline, S.R., Thomas, E.L. \& Swager, T.M. perpendicular organization of macromolecules: synthesis and alignment studies of a soluble poly(iptycene). J Am Chem Soc 127, 17976-17977 (2005).

93. Chen, Z., Amara, J.P., Thomas, S.W. \& Swager, T.M. Synthesis of a Novel Poly(iptycene) Ladder Polymer. Macromolecules 39, 3202-3209 (2006).

94. Wu, J.S., Gherghel, L., Watson, M.D., Li, J.X., Wang, Z.H., Simpson, C.D., Kolb, U. \& Mullen, K. From branched polyphenylenes to graphite ribbons. Macromolecules 36, 7082-7089 (2003).

95. Narita, A., Feng, X., Hernandez, Y., Jensen, S.A., Bonn, M., Yang, H., Verzhbitskiy, I.A., Casiraghi, C., Hansen, M.R., Koch, A.H., Fytas, G., Ivasenko, O., Li, B., Mali, K.S., Balandina, T., Mahesh, S., De Feyter, S. \& Mullen, K. Synthesis of structurally well-defined and liquid-phase-processable graphene nanoribbons. Nat Chem 6, 126-132 (2014).

96. Zhao, S., Rondin, L., Delport, G., Voisin, C., Beser, U., Hu, Y., Feng, X., Mullen, K., Narita, A., Campidelli, S. \& Lauret, J.S. Fluorescence from graphene nanoribbons of well-defined structure. Carbon 119, 235-240 (2017). 
97. Soavi, G., Dal Conte, S., Manzoni, C., Viola, D., Narita, A., Hu, Y., Feng, X., Hohenester, U., Molinari, E., Prezzi, D., Mullen, K. \& Cerullo, G.

Exciton-exciton annihilation and biexciton stimulated emission in graphene nanoribbons. Nat Commun 7, 11010 (2016).

98. Konnerth, R., Cervetti, C., Narita, A., Feng, X., Mullen, K., Hoyer, A., Burghard, M., Kern, K., Dressel, M. \& Bogani, L. Tuning the deposition of molecular graphene nanoribbons by surface functionalization. Nanoscale 7 , 12807-12811 (2015).

99. Abbas, A.N., Liu, G., Narita, A., Orosco, M., Feng, X., Mullen, K. \& Zhou, C. Deposition, characterization, and thin-film-based chemical sensing of ultra-long chemically synthesized graphene nanoribbons. J Am Chem Soc 136, 7555-7558 (2014).

100. Zschieschang, U., Klauk, H., Mueller, I.B., Strudwick, A.J., Hintermann, T., Schwab, M.G., Narita, A., Feng, X.L., Muellen, K. \& Weitz, R.T. Electrical Characteristics of Field-Effect Transistors based on Chemically Synthesized Graphene Nanoribbons. Adv Electron Mater 1, 1400010 (2015).

101. Fantuzzi, P., Martini, L., Candini, A., Corradini, V., del Pennino, U., Hu, Y., Feng, X., Mullen, K., Narita, A. \& Affronte, M. Fabrication of three terminal devices by ElectroSpray deposition of graphene nanoribbons. Carbon 104, 112-118 (2016).

102. Llinas, J.P., Fairbrother, A., Barin, G.B., Shi, W., Lee, K., Wu, S., Choi, B.Y., Braganza, R., Lear, J., Kau, N., Choi, W., Chen, C., Pedramrazi, Z., Dumslaff, T., Narita, A., Feng, X., Müllen, K., Fischer, F., Zettl, A., Ruffieux, P., Yablonovitch, E., Crommie, M., Fasel, R. \& Bokor, J. Short-Channel Field Effect Transistors with 9-Atom and 13-Atom wide Graphene Nanoribbons. arXiv:1605.06730 (2017).

103. Chen, Z.P., Zhang, W., Palma, C.A., Rizzini, A.L., Liu, B.L., Abbas, A., Richter, N., Martini, L., Wang, X.Y., Cavani, N., Lu, H., Mishra, N., Coletti, C., Berger, R., Klappenberger, F., Klaui, M., Candini, A., Affronte, M., Zhou, C.W., De Renzi, V., del Pennino, U., Barth, J.V., Rader, H.J., Narita, A., Feng, X.L. \& Mullen, K. Synthesis of Graphene Nanoribbons by Ambient-Pressure Chemical Vapor Deposition and Device Integration. Journal of the American Chemical Society 138, 15488-15496 (2016).

104. Narita, A., Verzhbitskiy, I.A., Frederickx, W., Mali, K.S., Jensen, S.A., Hansen, M.R., Bonn, M., De Feyter, S., Casiraghi, C., Feng, X. \& Mullen, K. Bottom-up synthesis of liquid-phase-processable graphene nanoribbons with near-infrared absorption. Acs Nano 8, 11622-11630 (2014). 
105. Tan, Y.Z., Yang, B., Parvez, K., Narita, A., Osella, S., Beljonne, D., Feng, X. $\&$ Mullen, K. Atomically precise edge chlorination of nanographenes and its application in graphene nanoribbons. Nat Commun 4, 2646 (2013).

106. Wu, M., Wang, J., Wu, Z.X., Xin, H.L.L. \& Wang, D.L. Synergistic enhancement of nitrogen and sulfur co-doped graphene with carbon nanosphere insertion for the electrocatalytic oxygen reduction reaction. $J$ Mater Chem A 3, 7727-7731 (2015).

107. Verzhbitskiy, I.A., Corato, M.D., Ruini, A., Molinari, E., Narita, A., Hu, Y., Schwab, M.G., Bruna, M., Yoon, D., Milana, S., Feng, X., Mullen, K., Ferrari, A.C., Casiraghi, C. \& Prezzi, D. Raman Fingerprints of Atomically Precise Graphene Nanoribbons. Nano Lett 16, 3442-3447 (2016).

108. Ivanov, I., Hu, Y., Osella, S., Beser, U., Wang, H.I., Beljonne, D., Narita, A., Mullen, K., Turchinovich, D. \& Bonn, M. Role of Edge Engineering in Photoconductivity of Graphene Nanoribbons. J Am Chem Soc 139, 7982-7988 (2017)

109. Dibble, D.J., Park, Y.S., Mazaheripour, A., Umerani, M.J., Ziller, J.W. \& Gorodetsky, A.A. Synthesis of polybenzoquinolines as precursors for nitrogen-doped graphene nanoribbons. Angew Chem Int Edit 54, 5883-5887 (2015).

110. Dossel, L., Gherghel, L., Feng, X.L. \& Müllen, K. Graphene Nanoribbons by Chemists: Nanometer-Sized, Soluble, and Defect-Free. Angewandte Chemie-International Edition 50, 2540-2543 (2011).

111. Kim, K.T., Jung, J.W. \& Jo, W.H. Synthesis of graphene nanoribbons with various widths and its application to thin-film transistor. Carbon 63, 202-209 (2013).

112. Kim, K.T., Lee, J.W. \& Jo, W.H. Charge-Transport Tuning of Solution-Processable Graphene Nanoribbons by Substitutional Nitrogen Doping. Macromolecular Chemistry and Physics 214, 2768-2773 (2013).

113. Schwab, M.G., Narita, A., Osella, S., Hu, Y.B., Maghsoumi, A., Mavrinsky, A., Pisula, W., Castiglioni, C., Tommasini, M., Beljonne, D., Feng, X.L. \& Mullen, K. Bottom-Up Synthesis of Necklace-Like Graphene Nanoribbons. Chem-Asian J 10, 2134-2138 (2015).

114. Li, G., Yoon, K.Y., Zhong, X.J., Zhu, X.Y. \& Dong, G.B. Efficient Bottom-Up Preparation of Graphene Nanoribbons by Mild Suzuki-Miyaura Polymerization of Simple Triaryl Monomers. Chem-Eur J 22, 9116-9120 (2016).

115. Yang, W.L., Lucotti, A., Tommasini, M. \& Chalifoux, W.A. Bottom-Up Synthesis of Soluble and Narrow Graphene Nanoribbons Using Alkyne 
Benzannulations. Journal of the American Chemical Society 138, 9137-9144 (2016).

116. Schwab, M.G., Narita, A., Hernandez, Y., Balandina, T., Mali, K.S., De Feyter, S., Feng, X.L. \& Mullen, K. Structurally Defined Graphene Nanoribbons with High Lateral Extension. Journal of the American Chemical Society 134, 18169-18172 (2012).

117. El Gemayel, M., Narita, A., Dossel, L.F., Sundaram, R.S., Kiersnowski, A., Pisula, W., Hansen, M.R., Ferrari, A.C., Orgiu, E., Feng, X.L., Mullen, K. \& Samor, P. Graphene nanoribbon blends with P3HT for organic electronics. Nanoscale 6, 6301-6314 (2014).

118. Vo, T.H., Shekhirev, M., Kunkel, D.A., Morton, M.D., Berglund, E., Kong, L.M., Wilson, P.M., Dowben, P.A., Enders, A. \& Sinitskii, A. Large-scale solution synthesis of narrow graphene nanoribbons. Nature Communications 5(2014).

119. Jordan, R.S., Wang, Y., McCurdy, R.D., Yeung, M.T., Marsh, K.L., Khan, S.I., Kaner, R.B. \& Rubin, Y. Synthesis of Graphene Nanoribbons via the Topochemical Polymerization and Subsequent Aromatization of a Diacetylene Precursor. Chem 1, 78-90 (2016). 